\author{
MORTALITY, FERTILITY, EDUCATION AND \\ CAPITAL \\ ACCUMULATION IN A SIMPLE OLG ECONOMY
}

Alexander Ludwig and Edgar Vogel

179-2009

( ) Mea-Mannheim Research Institute for the Economics of Aging

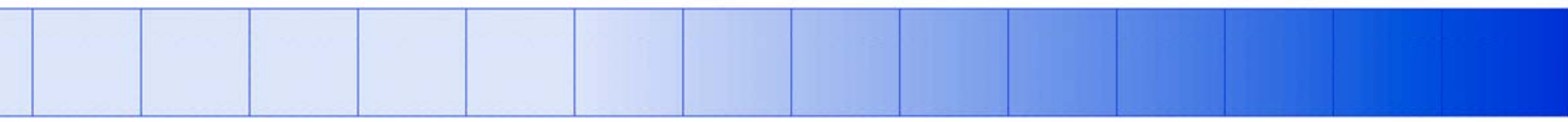

L13, 17_D-68131 Mannheim_Phone +49 621 181-2773/1862_Fax +49 621 181-1863_www.mea.uni-mannheim.de 


\title{
Mortality, Fertility, Education and Capital Accumulation in a Simple OLG Economy*
}

\author{
Alexander Ludwig ${ }^{\dagger} \quad$ Edgar Vogel ${ }^{\ddagger}$
}

April 15, 2009

\begin{abstract}
We develop a simple overlapping generations model to analytically show that population aging leads to increased educational efforts through a general equilibrium effect. The key mechanism at work in the model is that scarcity of raw labor increases the rate of return to human capital relative to physical capital. While a reduction in the birth rate is shown to unambiguously increase educational efforts, increases in the survival rate have ambiguous effects. Falling birth rates unambiguously increase capital per worker while the effects of rising survival rates are ambiguous. When evaluating our model using a calibrated version we find that education always increases if life expectancy rises but the effect on the capital stock is still ambiguous and depends on the parameters of the model. We conclude that our model is a useful laboratory to highlight the various potentially offsetting effects at work in models with endogenous education and overlapping generations which is key for understanding the magnitudes of results of applied quantitative general equilibrium analyses employing such a framework.
\end{abstract}

JEL classification: I12, I20, J11, J24, O11

Keywords: Mortality, Fertility, Aging, Education, OLG

*We thank Wolfgang Kuhle and Thomas Schelkle for helpful comments. Financial support by the State of Baden-Württemberg and the German Insurers Association (GDV) is gratefully acknowledged.

${ }^{\dagger}$ Mannheim Research Institute for the Economics of Aging (MEA); Universität Mannheim; L13, 17; 68131 Mannheim; Germany; Email: ludwig@mea.uni-mannheim.de.

${ }_{\ddagger}^{\ddagger}$ Mannheim Research Institute for the Economics of Aging (MEA); Universität Mannheim; CDSE; L13, 17; 68131 Mannheim; Germany; Email: vogel@mea.uni-mannheim.de. 


\section{Introduction}

Important aspects of economic history are the decline in mortality, the associated increase in life expectancy and a notable rise in investment into human capital. Life expectancy at birth in the UK was about 40 years in 1850, 65 years in 1950 and rose by 10 more years until the year 2000 (Cutler et al. 2006). The share of children aged 10-14 attending primary schools rose from $10 \%$ in 1820 to $80 \%$ in 1930 (Flora et al. 1983). Universal schooling was reached soon thereafter. The same development took place for secondary and tertiary education. Net enrollment rates for secondary schooling increased from $67 \%$ in 1970 to $95 \%$ in 2000 (The World Bank 2004). As can be seen, these process of rising life expectancy, falling birth rates and investment into human capital are still going on in modern economies. The combined effect is that the population structure of developed countries is changing rapidly with a rising share of elderly people. This rise of the old-age dependency ratio and the associated rise in social security contributions have shifted the "aging problem" into the focus of the academic literature as well as public policy.

In this paper we develop an analytically tractable two generations OLG model in the spirit of Diamond (1965) in order to study the effects of demographic change on educational investment decisions and capital accumulation. We augment the simple textbook model with endogenous human capital formation. Population dynamics - the exogenous driving force of our model - are modeled by considering uncertain survival to old age and birth rates separately. Additionally, we look at the effects of changing lifetime labor supply. The strength of our setup is that we can analyze the general equilibrium effects of population dynamics using closed form solutions. The contribution of our paper is that using this rich setup, we are able to show that changes in life expectancy, population growth and lifetime labor supply have, in general, ambiguous effects on the capital stock and education. We demonstrate that it is key to consider the interactions between annuity markets, the pension system and productivity of education for understanding the qualitative and quantitative effects of variations in the population structure on changes in physical and human capital accumulation.

The relationship between mortality and investment into human capital has been investigated is a number of theoretical and empirical studies. Empirical studies find that falling mortality and the associated rise in life expectancy increase investment into human capital. Using data for post-war India, Ram and Schultz (1979) find that improvements in mortality played a major role in the rise of educational attainment. Eckstein et al. (1999) provide evidence for Sweden that the fall in child mortality was the most important factor for the demographic transition and the rising educational attainment. On the other hand, Mincer (1995) and Foster and Rosenzweig (1996) present empirical evidence that rising education premia have a positive effect on schooling.

Theoretical work dealing with the ageing-education nexus by Boucekkine et al. (2002), de la Croix and Licandro (1999), Echevarria and Iza (2006) and Heijdra and Romp (2008) use variations of a Blanchard (1985) type of perpetual youth setup. By employing this model family the authors obtain closed form solutions and derive a number of insights by relying entirely on analytical results. These papers assume that the production processes 
use only labor (human capital) as an input or they consider only small open economies. Thus, the general equilibrium feedback effect of population dynamics on relative prices is ruled out by construction. A general conclusion of this literature is that increasing life expectancy increases investment into human and physical capital.

The papers by $\mathrm{Hu}$ (1999) and Kalemli-Ozcan et al. (2000) are closest in spirit to our work. They also employ a perpetual youth setup but overcome the limitations of the above mentioned papers by developing tractable general equilibrium models. Our contributions to their work are threefold. First, we do not only study the effects of changes in mortality but also the effects of changing fertility on investment in education and human as well as physical capital accumulation. Second, we also analyze how changes in the lifetime working horizon affect educational decisions and capital accumulation. This additional channel in our model stands in for a lifelong learning motive and is increasingly important in aging societies which reform their PAYG financed pension systems by increasing retirement ages. Third, by using an OLG rather than a perpetual youth model, we reconfirm some of the findings of the above mentioned authors: Rising survival rates may lead to increasing educational efforts and capital accumulation. However, we emphasize that there are potentially important offsetting effects. The lower degree of analytical tractability of our OLG model - in comparison to the perpetual youth model - buys us the possibility to include and to understand several interaction effects and to show how these may change results. For example, using an equilibrium relationship of their model, Kalemli-Ozcan et al. (2000) argue that the interest rate varies positively with mortality, "as would be expected from the simple intuition that shorter lives lead to lower wealth accumulation" (p. 11). We show that this positive effect is smaller when annuity markets are larger and that, by interpreting an equilibrium condition only, Kalemli-Ozcan et al. (2000) ignore two important and potentially offsetting effects: increasing mortality (i) decreases the workforce and (ii) may decrease educational efforts and both effects ceteris paribus lead to a negative variation of mortality and the interest rate.

Finally, Zhang, Zhang, and Lee (2001) add to this literature by modeling endogenous fertility and child education employing a two-generations OLG setup as we do but using a dynastic framework. These differences in the two approaches makes their work less suitable as a benchmark for comparison. Furthermore, as a consequence of the endogenous nature of fertility decisions, these authors cannot study the impact of changing fertility and mortality in isolation as we do.

The remainder of this paper is structured as follows. Section 2 introduces the model. The results of the comparative static analysis are derived in section 3. In the same section we also show the results of our calibration exercise where we perform an extensive sensitivity analysis. Some concluding remarks are in section 4. Separate appendices contain proofs and additional results. 


\section{The Model}

We develop a simple OLG model with endogenous education decisions and a PAYG financed social security system. The setup is as follows: agents live for two periods whereby survival to the second period is uncertain. In the first period agents choose time investment into education, saving and consumption. In the second period they consume their entire wealth and work only an exogenously given fraction $\omega$ of their time. The rest of their time (1 $\omega)$ they are retired and receive a lump-sum pension, $p_{t+1}$. We make this assumption for analytical tractability; it allows us to analyze the effects of different social security regimes in a model of human capital accumulation a la Ben-Porath (1967) within a 2-generations model. In this setup, the parameter $\omega$ reflects a motive for life-long learning which can be affected by policy, e.g., by increasing the retirement age.

\subsection{Demographics}

Each period, there are $N_{t, 0}$ young households and $N_{t, 1}$ old. Let $\gamma_{t}^{N}$ be the birth rate so that $N_{t, 0}=\gamma_{t}^{N} N_{t-1,0}$ and $s_{t}$ be the survival rate, hence $N_{t, 1}=s_{t} N_{t-1,0}$. Using these definitions, the old-age dependency ratio $\left(o a d r_{t}\right)$ - the fraction of the old to the young - in the economy is given by

$$
o a d r_{t}=\frac{N_{t, 1}}{N_{t, 0}}=\frac{s_{t}}{\gamma_{t}^{N}}
$$

\subsection{Markets for Annuities}

We assume the existence of (imperfect) annuity markets for insurance against survival risk. Let $a_{t, 0}$ be savings of the period $t$ young. Period $t+1$ asset holdings are consequently given by

$$
a_{t, 0}+\lambda a_{t, 0} \frac{1-s_{t+1}}{s_{t+1}}=a_{t, 0} \frac{\zeta_{t+1}}{s_{t+1}}
$$

where

$$
\zeta_{t+1} \equiv s_{t+1}+\lambda\left(1-s_{t+1}\right)
$$

is an annuity factor introduced here for convenience and $0 \leq \lambda \leq 1$ is the degree of annuitization, also see Hansen and İmrohoroğlu (2008). Notice that, in the case of no annuitization, we have $\lambda=0$ and $\zeta_{t+1}=s_{t+1}$ and for complete (perfect) annuity markets we have $\lambda=1$ and $\zeta_{t+1}=1$. Full annuitization implies that the assets of the deceased agents are distributed uniformly among the surviving old agents which is an insurance against longevity (Yaari 1965).

Without annuity markets there is no "insurance effect" but agents receive a lump-sum payment $t r_{t+1}$ from the government. To keep the analysis analytically tractable we assume that in the case of incomplete annuitization the government distributes the accidental 
bequests to the old. ${ }^{1}$ Accidental bequests are then redistributed to households as lumpsum transfers and given by

$$
t r_{t+1}=(1-\lambda) \frac{a_{t, 0}\left(1+r_{t+1}\right)\left(1-s_{t+1}\right) N_{t, 0}}{N_{t+1,1}} .
$$

and, using the fact that

$$
N_{t+1,1}=N_{t, o} s_{t+1}
$$

we have

$$
t r_{t+1}=(1-\lambda) \frac{a_{t, 0}\left(1+r_{t+1}\right)\left(1-s_{t+1}\right)}{s_{t+1}}
$$

\subsection{Household Optimization}

Households maximize expected lifetime utility

$$
\max _{c_{t, 0}, c_{t+1,1}} \log c_{t, 0}+\beta s_{t+1} \log c_{t+1,1}
$$

subject to the constraints

$$
\begin{aligned}
c_{t, 0}+a_{t, 0} & =\left(1-e_{t}\right) h_{0} w_{t}\left(1-\tau_{t}\right) \\
c_{t+1,1} & =\frac{\left(1+r_{t+1}\right) \zeta_{t+1}}{s_{t+1}} a_{t, 0}+\omega h_{t+1,1} w_{t+1}\left(1-\tau_{t+1}\right)+(1-\omega) p_{t+1}+t r_{t+1},
\end{aligned}
$$

where $\beta$ is the raw time discount factor, $e_{t}$ is investment into education when young, $h_{0}$ is the stock of human capital given at birth (taken as exogenous and constant over cohorts), $w_{t}$ is the wage rate per unit of human capital, $r_{t+1}$ is the return on financial assets, $\tau_{t}$ denotes the social security contribution rate, $p_{t+1}$ are lump-sum pension payments, and $t r_{t+1}$ are the distributed accidental bequests.

Due to the representative agent setup, two interpretations of $\omega$ are conceivable. In the first interpretation $\omega$ is the fraction of time the representative agent of age 1 works. In the second, it is the fraction in the population of age 1 that works. Either way, $\omega$ works like a policy variable and a change in $\omega$ could be interpreted, e.g., as a change in retirement legislation or labor market incentives affecting participation rates.

The present value budget constraint is accordingly given by

$$
\begin{aligned}
c_{t, 0}+s_{t+1} \frac{c_{t+1,1}}{\zeta_{t+1}\left(1+r_{t+1}\right)}= & \\
& \left(1-e_{t}\right) h_{0} w_{t}\left(1-\tau_{t}\right)+s_{t+1} \frac{\omega h_{t+1,1} w_{t+1}\left(1-\tau_{t+1}\right)+(1-\omega) p_{t+1}+t r_{t+1}}{\zeta_{t+1}\left(1+r_{t+1}\right)} .
\end{aligned}
$$

${ }^{1}$ To see why this assumption is useful assume that bequests are distributed to the young. Then, transfers are given by

$$
t r_{t}=(1-\lambda) \frac{a_{t-1,0}\left(1+r_{t}\right)\left(1-s_{t}\right) N_{t-1,0}}{N_{t, 0}}=(1-\lambda) a_{t-1,0}\left(1+r_{t}\right) \frac{1-s_{t}}{\gamma_{t}^{N}} .
$$

As $a_{t-1,0}$ shows up in the above equation, the analysis would involve a second-order difference equation for $k_{t}$ which would tremendously reduce analytical tractability. Assuming that bequests are distributed to the young and old will obviously cause the same problem. 
The education technology is

$$
h_{t+1,1}=\left(1+g\left(e_{t}\right)\right) h_{0},
$$

with $g$ being a function mapping educational investment into formation of human capital. We choose $g$ such that it is increasing, concave in $e$ and fulfills the lower Inada condition. These are standard assumptions about the education function (see Willis (1986)). ${ }^{2}$ Later, we specify a parametric form for $g\left(e_{t}\right)$ to obtain a closed form solution. Solving the maximization problem gives the Euler equation

$$
c_{t+1,1}=\beta \zeta_{t+1}\left(1+r_{t+1}\right) c_{t, 0} .
$$

Solving for the optimal educational investment gives

$$
g^{\prime}\left(e_{t}\right)=\frac{\zeta_{t+1}\left(1+r_{t+1}\right)}{s_{t+1}} \frac{w_{t}\left(1-\tau_{t}\right)}{\omega w_{t+1}\left(1-\tau_{t+1}\right)}
$$

This condition says that an individual invests into schooling until the marginal return of schooling equals the return on net wages relative to the effective interest rate. Following Bouzahzah et al. (2002), we define the education function $g\left(e_{t}\right)$ in $(9)$ as

$$
g\left(e_{t}\right)=\xi e_{t}^{\psi}, \quad \text { where } 0<\psi<1, \xi>0 .
$$

Optimal education is then given by

$$
e_{t}=\left[\omega \xi \psi \frac{w_{t+1}\left(1-\tau_{t+1}\right)}{w_{t}\left(1-\tau_{t}\right)} \frac{s_{t+1}}{\zeta_{t+1}\left(1+r_{t+1}\right)}\right]^{\frac{1}{1-\psi}} .
$$

It can be seen that educational decisions depend positively on the ratio of net wage growth to the return on capital holdings. This is the key general equilibrium effect we are interested in. The scarcity of raw labor resulting from demographic change will lead to rising wages and falling interest rates. According to equation (13) this will induce general equilibrium feedback effects by leading to increases in education and thereby to an increase in the second period human capital.

In addition to these general equilibrium effects, equation (13) shows direct effects on educational efforts through the educational productivity, $\xi$ and $\psi$, the fraction of time working in the second period, $\omega$ and the probability of survival if there is some annuitization, i.e., if $\lambda>0$. The direct effect of survival on educational decisions has in part been labeled as an effect due to an extension of the adult planning horizon, e.g., by Heijdra and Romp (2008). This is a misleading interpretation because the direct effect of survival is in fact a result of the induced adjustment of the rate of return to physical capital if

\footnotetext{
${ }^{2}$ For analytical reasons, we assume zero depreciation of human capital and we do not make $h$ an argument of $g$ as in the standard Ben-Porath (1967) technology. This parametric restriction is also superimposed in some empirical studies, see the review in Browning, Hansen, and Heckman (1999).
} 
there is some annuitization. ${ }^{3}$ In the absence of annuitization, there is no adjustment of the rate of return to physical capital to the survival rate and changes in the survival rate have a direct effect only on the inter-temporal allocation of consumption (via the changing effective discount rate $s_{t+1} \beta$ ). In our model, the "pure" effect of extending the planing horizon is represented by an increase in $\omega$.

Finally, households' optimal consumption follows from using (10) in (8) as

$$
\begin{aligned}
c_{t, 0} & = \\
& \frac{1}{1+\beta s_{t+1}}\left(\left(1-e_{t}\right) h_{0} w_{t}\left(1-\tau_{t}\right)+s_{t+1} \frac{\omega h_{t+1,1} w_{t+1}\left(1-\tau_{t+1}\right)+(1-\omega) p_{t+1}+t r_{t+1}}{\zeta_{t+1}\left(1+r_{t+1}\right)}\right)
\end{aligned}
$$

and using the above in (7a) gives savings as

$$
\begin{aligned}
a_{t, 0}=\frac{1}{1+\beta s_{t+1}}\left(\beta s_{t+1}\left(1-e_{t}\right) h_{0} w_{t}\left(1-\tau_{t}\right)-\right. \\
\left.s_{t+1} \frac{\omega h_{t+1,1} w_{t+1}\left(1-\tau_{t+1}\right)+(1-\omega) p_{t+1}+t r_{t+1}}{\zeta_{t+1}\left(1+r_{t+1}\right)}\right) .
\end{aligned}
$$

\section{$2.4 \quad$ Firms}

Firms produce output using a standard Cobb-Douglas production function

$$
Y_{t}=K_{t}^{\alpha}\left(A_{t} L_{t}\right)^{1-\alpha}
$$

$A_{t}$ is the firm's technology level which is determined by

$$
A_{t+1}=A_{t} \gamma^{A}
$$

where $\gamma^{A}$ is the exogenous gross growth rate. $L_{t}$ is effective labor input which is the sum of human capital weighted labor supply of the young and of the old and accordingly given by

$$
L_{t}=\left(1-e_{t}\right) h_{0} N_{t, 0}+\omega h_{t, 1} N_{t, 1}
$$

Competitive markets ensure that factors get paid their marginal products. We assume that capital depreciates fully after one period so that

$$
\begin{aligned}
1+r_{t} & =\alpha k_{t}^{\alpha-1} \\
w_{t} & =(1-\alpha) A_{t} k_{t}^{\alpha},
\end{aligned}
$$

where $k_{t} \equiv \frac{K_{t}}{A_{t} L_{t}}$.

\footnotetext{
${ }^{3}$ This has already been shown by $\mathrm{Hu}(1999)$.
} 


\subsection{Government}

The role of the government is twofold. First, the government taxes accidental bequests in the case of incomplete annuitization at a confiscatory rate and redistributes them as lumpsum payments to the old. Second, the government runs a PAYG financed social security system with a balanced budget in all periods requiring that total contributions by workers equal total pension payments. ${ }^{4}$ By equation (17) we then have

$$
w_{t} \tau_{t}\left(\left(1-e_{t}\right) h_{0} N_{t, 0}+\omega h_{t, 1} N_{t, 1}\right)=(1-\omega) p_{t} N_{t, 1} .
$$

Notice that the above, using equation (1), implies that

$$
(1-\omega) p_{t}=w_{t} \tau_{t}\left(\left(1-e_{t}\right) h_{0} \frac{\gamma_{t}^{N}}{s_{t}}+\omega h_{t, 1}\right)
$$

Changes in the population structure require adjustments of the social security policy. Let $\varrho_{t}$ denote the replacement rate, i.e., the ratio of pension income to average net wage income. Then pension income can be expressed as

$$
p_{t}=\varrho_{t} \frac{\left(1-\tau_{t}\right) w_{t}\left(\left(1-e_{t}\right) h_{0} N_{t, 0}+\omega h_{t, 1} N_{t, 1}\right)}{N_{t, 0}+\omega N_{t, 1}} .
$$

Using the above definition in (19) and simplifying then links contribution and replacement rates by

$$
\tau_{t}=\frac{(1-\omega) \varrho_{t}}{\gamma_{t}^{N} / s_{t}+\omega+(1-\omega) \varrho_{t}} .
$$

It can be readily observed that $\tau_{t}$ increases in the fraction of pensioners, $1-\omega$, the generosity of the pension system, $\varrho_{t}$, and in the old-age dependency ratio, $s_{t} / \gamma_{t}^{N}$. Using this setup, fixing $\tau_{t}=\bar{\tau}$ corresponds to a fixed contribution rate system and holding $\varrho_{t}=\bar{\varrho}$ corresponds to a fixed replacement rate system. ${ }^{5}$

\subsection{Equilibrium}

In equilibrium all markets clear, households maximize utility and firms make zero profits. Market clearing on the capital market requires that

$$
K_{t+1}=a_{t, 0} N_{t, 0} .
$$

Using (1) in (17), aggregate labor supply can be rewritten as

$$
L_{t}=N_{t, 0} h_{0}\left(\left(1-e_{t}\right)+\omega \frac{s_{t}}{\gamma_{t}^{N}}\left(1+g\left(e_{t-1}\right)\right)\right) .
$$

\footnotetext{
${ }^{4}$ While we explicitly model this inter-generational transfer system as a pension system, it may also be interpreted as a metaphor for a more general intergenerational transfer system, e.g., a health care system.

${ }^{5}$ Notice that these definitions are not the same as what is referred to as defined contribution and defined benefit systems in the literature.
} 
Collecting elements, the following proposition gives the law of motion of the aggregate economy.

Proposition 1. For given $k_{0}$ the aggregate dynamics of the economy are described by the system of first-order difference equations in $\left\{k_{t}, e_{t}\right\}$ given by

$$
\begin{gathered}
k_{t+1}=\frac{\varphi_{t} \alpha(1-\alpha)\left(1-\tau_{t}\right)}{\phi_{t}} k_{t}^{\alpha} \\
e_{t}=\left(\frac{s_{t+1}}{\zeta_{t+1}} \omega \xi \psi \frac{\gamma^{A}\left(1-\tau_{t+1}\right) k_{t+1}}{\alpha\left(1-\tau_{t}\right) k_{t}^{\alpha}}\right)^{\frac{1}{1-\psi}},
\end{gathered}
$$

where

$$
\begin{aligned}
\phi_{t} \equiv \gamma^{A}\left(\left(\alpha\left(2+\hat{\rho}_{t+1}\right)+\right.\right. & \left.\varphi_{t} \frac{(1-\alpha) \tau_{t+1}}{\zeta_{t+1}}\left(1+\hat{\rho}_{t+1}\right)\right) \frac{1-e_{t+1}}{1-e_{t}} \gamma_{t+1}^{N} \\
& \left.+\omega s_{t+1}\left(\alpha\left(2+\hat{\rho}_{t+1}\right)+\varphi_{t} \frac{1-\alpha}{\zeta_{t+1}}\left(1+\hat{\rho}_{t+1}\right)\right) \frac{1+g\left(e_{t}\right)}{1-e_{t}}\right) \\
\varphi_{t} \equiv & \frac{\left(2+\hat{\rho}_{t+1}\right) \zeta_{t+1}}{\left.\left(2+\hat{\rho}_{t+1}\right) \zeta_{t+1}+\left(1-s_{t+1}\right)(1-\lambda)\right)}
\end{aligned}
$$

and $\hat{\rho}_{t+1}=\frac{1}{s_{t+1} \beta}-1$.

Proof. Relegated to the appendix.

Proposition 2. If there is an equilibrium, education $e_{t}$ is always interior on the interval $(0,1)$. Further, education converges always to its steady state value.

Proof. Relegated to the appendix.

\subsection{Steady State Analysis}

Definition 1. Along the balanced growth path (steady state) of the economy, all variables grow at constant rates so that $k=k_{t+1}=k_{t}$ and $e=e_{t+1}=e_{t} \forall t$.

Proposition 3. For $0<\alpha<1$ and $0 \leq \tau<1$, the unique steady state of the economy is given by

$$
\begin{gathered}
k=\left(\frac{\varphi \alpha(1-\alpha)(1-\tau)}{\phi}\right)^{\frac{1}{1-\alpha}} \\
e=\left(\omega \xi \psi \frac{\gamma^{A}}{\alpha}\right)^{\frac{1}{1-\psi}}\left(\frac{s}{\zeta}\right)^{\frac{1}{1-\psi}} k^{\frac{1-\alpha}{1-\psi}}
\end{gathered}
$$


where

$$
\begin{aligned}
& \phi \equiv \gamma^{A}\left(\left(\alpha(2+\hat{\rho})+\varphi \frac{(1-\alpha) \tau}{\zeta}(1+\hat{\rho})\right) \gamma^{N}+\right. \\
&\left.\quad+\omega s\left(\alpha(2+\hat{\rho})+\varphi \frac{1-\alpha}{\zeta}(1+\hat{\rho})\right) \frac{1+g(e)}{1-e}\right) \\
& \varphi \equiv \frac{(2+\hat{\rho}) \zeta}{(2+\hat{\rho}) \zeta+(1-s)(1-\lambda)}
\end{aligned}
$$

and $\hat{\rho}=\frac{1}{s \beta}-1$.

Proof. Relegated to the appendix.

\section{Comparative Statics}

In this section, we use our framework to study the effects of demographic change on the economy by conducting a comparative statics analysis in steady state. In this respect our model is a useful laboratory to provide intuition for the results of much of the quantitative work, e.g., by Fougère and Mérette (16), Sadahiro and Shimasawa (2002), Bouzahzah et al. (2002) and Ludwig et al. (2008). To this end, we analyze - by looking at partial derivatives - the effects of changing fertility, mortality and working time on the capital stock and education. We first do so in a social security scenario with constant contributions rates and then consider the opposite extreme by holding replacement rates constant. While we can uniquely determine the signs of many partially derivatives, we fail to do so in some cases. In these cases, our closed form solutions help us to understand the various offsetting effects at work and to detect the sources of indeterminacy. Finally, we use a calibrated version of our model to illustrate how the signs of partial derivatives depend on the parametrization of the model in the ambiguous cases.

\subsection{Analytical Results}

We drop the time indices to indicate steady state values. To begin with, we provide analytical results followed by an interpretation. Detailed proofs are available in the appendix.

Proposition 4. In the steady state of the economy we have

1. for $\tau=\bar{\tau}$ that

$$
\begin{aligned}
& \left.\frac{\partial k}{\partial \gamma^{N}}\right|_{\tau=\bar{\tau}}<0 \text { and }\left.\frac{\partial e}{\partial \gamma^{N}}\right|_{\tau=\bar{\tau}}<0, \\
& \left.\frac{\partial k}{\partial s}\right|_{\tau=\bar{\tau}} \gtrless 0 \text { and }\left.\quad \frac{\partial e}{\partial s}\right|_{\tau=\bar{\tau}} \gtrless 0 \text {. } \\
& \left.\frac{\partial k}{\partial \omega}\right|_{\tau=\bar{\tau}}<0 \text { and }\left.\frac{\partial e}{\partial \omega}\right|_{\tau=\bar{\tau}} \gtrless 0 \text {, }
\end{aligned}
$$


2. For the relationship between the cases $\tau=\bar{\tau}$ and $\varrho=\bar{\varrho}$ we have that

$$
\begin{gathered}
\left.\frac{\partial k}{\partial \gamma^{N}}\right|_{\varrho=\bar{\varrho}}>\left.\frac{\partial k}{\partial \gamma^{N}}\right|_{\tau=\bar{\tau}} \text { and }\left.\frac{\partial e}{\partial \gamma^{N}}\right|_{\varrho=\bar{\varrho}}>\left.\frac{\partial e}{\partial \gamma^{N}}\right|_{\tau=\bar{\tau}} \\
\left.\frac{\partial k}{\partial s}\right|_{\varrho=\bar{\varrho}}<\left.\frac{\partial k}{\partial s}\right|_{\tau=\bar{\tau}} \text { and }\left.\frac{\partial e}{\partial s}\right|_{\varrho=\bar{\varrho}}<\left.\frac{\partial e}{\partial s}\right|_{\tau=\bar{\tau}}, \\
\left.\frac{\partial k}{\partial \omega}\right|_{\varrho=\bar{\varrho}}>\left.\frac{\partial k}{\partial \omega}\right|_{\tau=\bar{\tau}} \text { and }\left.\frac{\partial e}{\partial \omega}\right|_{\varrho=\bar{\varrho}}>\left.\frac{\partial e}{\partial \omega}\right|_{\tau=\bar{\tau}},
\end{gathered}
$$

Proof. Relegated to the appendix.

Interpretation of the partial derivatives of the capital stock and education in equation (28a) is rather straightforward. First, observe from (26b) that there is no direct effect of the birth rate, $\gamma^{N}$, on the education decision, $e$. Second, an increase of the birth rate increases the effective supply of labor in the economy which decreases $k$, cf. (26a) and (27a). Therefore, a change in the birth rate affects the relative prices of physical and human capital through its effect on $k$. An increase of $k$ increases the wage rate, $w$, and decreases the return on physical capital, $r$. While the growth rate of wages $\left(\frac{w_{t+1}}{w_{t}}\right)$ is unchanged in our steady state comparison, the return on physical capital decreases. Consequently, optimal education goes up, cf. (13).

As stated in the proposition, the signs of the partial derivatives in (28b) cannot be determined unambiguously. First, notice that there are various effects from increases of $s$ on savings and thus $k$ at work, cf. (27a): (i) an increase of $s$ decreases the effective discount rate $\hat{\rho}$ which increases $k$. This is so because an increase of the survival rate increases savings via its effect on current period income, cf. the first term in the brackets of (14). (ii), however, an increase in the survival rate also increases the value of second period income as long as $\lambda>0$ (so that $s_{t+1} / \zeta_{t+1}<1$ ) which dampens the increase of savings. This dampening effect is the stronger, the larger is the size of the annuity market, i.e., the higher is $\lambda .^{6}$ (iii) for $\lambda>0$, there is a direct effect of survival on education, cf. (26b), which varies positively with $\lambda$. This increases effective labor supply and thereby tends to decrease $k$. (iv) as $s$ increases, raw labor supply increases as long as $\omega>0$. Observe that the last two effects are stronger when the average human capital productivity is high, because $\omega$ interacts with $\xi$ via the term $\frac{1+g(e)}{1-e}$ in $(27 \mathrm{a})$.

This discussion explains why the signs of the effects of $s$ on $k$ cannot be determined unambiguously. It can only be said that the capital stock is likely to increase if $\omega, \lambda$ and $\xi$ are sufficiently small. For too high values of these parameters, the reaction of effective labor supply is too strong and the capital stock $k_{t}$ may decrease (so that $r_{t+1}$ increases). Second, this ambiguity with respect to the effects of $s$ on $k$ translates into an ambiguous effect of $s$ on $e$, cf. (26b). However, even if $k$ varies negatively with $s$, education may

\footnotetext{
${ }^{6}$ As can be immediately observed from (14), the overall effect of increasing survival on savings is unambiguously positive. But it is larger for $\lambda=0$ than for $\lambda=1$.
} 
still increase because of the direct effect of increasing survival on the education decision in the presence of annuity markets $(\lambda>0)$. Indeed, in all of our simulations of subsection 3.3 , schooling is found to increase if $s$ rises, also in those cases in which $k$ decreases when annuity markets are perfect. On the contrary, with missing annuity markets, we never find that $k$ decreases in $s$ so that there is also no ambiguity in the resulting educational adjustments.

The effect of a changing lifetime labor supply $\omega$ given in equation $(28 \mathrm{c})$ is unambiguously negative for the capital stock but ambiguous for the optimal education decision. First, increasing $\omega$ increases total effective labor supply and thus decreases $k$. Second, an increase of $\omega$ has a direct effect on education, cf. (13). This leads to an additional increase of effective labor which further decreases $k$. However, third, a decrease of $k$ also exerts a dampening effect on education by increasing the return on physical capital. As this third effect is only a second order general equilibrium feedback effect, it cannot offset the decrease of $k$ which explains the unambiguous sign for the partial derivative of $k$. However, the direct effect of $\omega$ on $k$ and the resulting general equilibrium price effect could potentially be strong enough to offset the direct effect of $\omega$ on education. This explains the ambiguous sign of the partial derivative of $e$. While this is so analytically, we show below for a wide range of parameter constellations of our simulations that education varies positively with $\omega$.

The effect of an adjustment of the contribution rate $\tau$ is examined in the second part of proposition 4 . Recall that changing the contribution rate has only a direct effect on capital accumulation but does not distort education decisions in steady state. Thus, increasing the contribution rate only has an effect on steady state education to the extent that it crowds out savings in physical capital. The uniform conclusion is therefore that a rising (falling) contribution rate decreases (increases) the capital stock, thereby increases (decreases) the interest rate and thus decreases (increases) the incentives to invest into education. A brief verbal summary of the results is that the effect of falling birth rates, rising survival rates, i.e., an aging of the population, or an extension of the lifetime labor supply has a larger effect (in absolute values) on the capital stock and on education if the contribution rate $\tau$ is held constant. The results do not say, however, that the signs do not change. Since we add one layer of complexity, it is even harder to pin down the direction of change.

\subsection{Role of annuity markets}

This subsection discusses the role of the degree of annuitization in more detail. We show in the appendix that

Proposition 5. In the steady state of the economy we have

1. for $\tau=\bar{\tau}$ that

$$
\left.\frac{\partial k}{\partial \lambda}\right|_{\tau=\bar{\tau}}>0 \text { and }\left.\quad \frac{\partial e}{\partial \lambda}\right|_{\tau=\bar{\tau}} \gtrless 0,
$$

2. For the relationship between the cases $\tau=\bar{\tau}$ and $\varrho=\bar{\varrho}$ we have that 


$$
\left.\frac{\partial k}{\partial \lambda}\right|_{\varrho=\bar{\varrho}}=\left.\frac{\partial k}{\partial \lambda}\right|_{\tau=\bar{\tau}} \text { and }\left.\quad \frac{\partial e}{\partial \lambda}\right|_{\varrho=\bar{\varrho}}=\left.\frac{\partial e}{\partial \lambda}\right|_{\tau=\bar{\tau}} .
$$

Proof. Relegated to the appendix.

More complete annuity markets increase savings but have an ambiguous effect on the education decision. Again, the ambiguity comes from the fact that the direct effect of increasing annuitization on the interest rate - which reduces educational investments, c.f. equation (26b) - may be offset by the indirect effect of rising capital — which decreases the interest rate and thereby increases education. Furthermore, the effect of $\lambda$ on capital and education is the same in both social security scenarios. This is so because the adjustment of the contribution or replacement rate does not interact with $\lambda$.

More interesting is, however, how the level of $\lambda$ interacts with the derivatives of $k$ and $e$ with respect to $s, \gamma^{N}$ and $\omega$. Unfortunately, due to the algebraic complexity of the problem, it is not possible to obtain clear results for these cross-derivatives. However, as is shown in appendix $\mathrm{A}$, a higher $\lambda$ makes it more likely that $\partial k / \partial s<0$. Further results on the importance of annuity markets are illustrated in our numerical simulations, cf., in particular, the discussion in subsection 3.3.2.

\subsection{Numerical Results}

As stated in the previous subsection, there are cases in which the sign of the derivatives are ambiguous. For these cases we here present results from numerical simulations of our model to illustrate the sources for this ambiguity. Obviously, our stylized two period model fails to capture many relevant aspects. This exercise is therefore an illustration only and is not meant to provide exact quantitative results of population aging on the economy. We first investigate the case with perfect annuity markets and then the case without annuity markets. Furthermore, we redo the calculations for both scenarios with constant contribution and constant replacement rates.

\subsubsection{Perfect Annuity Markets}

In this subsection we focus on the case with perfect annuity markets $(\lambda=1)$ where the direct effects of changing survival rates on the education decision is strongest and consequently the effects of changing survival are likely to be ambiguous, cf. our previous discussion in subsection 3.1 and the appendix. Furthermore, the case with perfect annuity markets, although empirically doubtful, makes our results directly comparable to the perpetual youth model of Kalemli-Ozcan et al. (2000).

We take the periodicity of the model such that each generation covers a maximum of 40 years. Agents are assumed to become economically active at the actual age of 20 . Correspondingly, the maximum age agents can reach is 100. Our calibration targets for some of the population parameters are for averages of the three core European countries 
France, Germany and Italy. ${ }^{7}$ For the survival rate, $s$, we take as calibration target the remaining life expectancy at the age of $20, L E_{20}$, which is currently (in 2004) 68 years. As survival in our model is certain in the first period of life, the survival rate is given by $s=L E_{20} / 40-1.0=0.69$. We calibrate $\gamma^{N}$ using the implied $\gamma^{N}$ to match the old-age dependency ratio of $44 \%$. Accordingly, we set $\gamma^{N}=1.5574 .{ }^{8}$ The long-run growth rate of productivity in European countries is roughly 0.015 (Barro and Sala-i-Martin 2003) annually so that $\gamma^{A}=1.015^{40}=1.81$. We set the discount factor $\beta=0.99^{40}=0.67$ by reference to other studies, e.g., Hurd (1990).

The most critical parameters are $\omega$ and $\psi$, and $\xi$. First, we calibrate $\psi$ to medium value of the estimates reported in Browning, Hansen, and Heckman (1999) which is 0.6. Second, there is no direct empirical counterpart of $\omega$ because it just reflects an auxiliary variable in our model that simplifies the exposition. To calibrate this parameter we use the share of agents obtaining higher education as the calibration target. ${ }^{9}$ Since the timing of the model is such that the first (and economically passive) period is 20 years, education can be also viewed as the share of people investing into higher education (university and post-graduate education). We construct aggregate indices using data from OECD (2008). ${ }^{10}$ The procedure is as follows. We compute the average graduation age of a typical student for the two university (or equivalent) diploma categories (Type A and B). Then we use this number to compute how many years a person spends in tertiary education in excess of the economic starting age (which is set to 20). For example, the "average" French student (see table 1 ) is obtaining a type A diploma at the age of 24.5 and a type B diploma at the age of 22. We then weight the "excess years" (4.5 and 2) by the population weights (0.11 and $0.15)$ to obtain years of tertiary education of a representative French agent (0.775). Then, we weight the country specific years by the population of the three countries to compute years of education for the "representative European" (0.874). As a last step, we divide this number by the duration of one period (40 years) to convert it into the model specific equivalent and use it as a calibration target. Hence, our target for $e$ is $e=0.01988$. Third, we calibrate $\xi$ endogenously to match the ratio of peak life cycle wages to the wage rate at labor market entry which is 1.6 (Attanasio 1999). Since we set $h_{0}=1$, this is the data equivalent to human capital holdings of the old, $h_{1}$, and our calibration target requires $\xi=6.30$. Parameters are summarized in table 2 .

As our discussion of the analytical results in subsection 3.1 shows, the most critical parameters in the case of perfect annuitization $(\lambda=1)$ are $s, \omega, \xi, \psi$. We therefore consider a range of alternative specifications around the benchmark specification in table 2 for all

\footnotetext{
${ }^{7}$ Our population data are based on the Human Mortality Database (2008).

${ }^{8}$ The alternative would be to calibrate $\gamma^{N}$ with the gross growth rate of the working age population ratio. This would require to set $\gamma^{N}=1.06$. The implied oadr is then 0.66 and hence this alternative would overestimate the actual old-age dependency.

${ }^{9}$ Alternative calibration targets are e.g. the fraction of the old (age 60 and older) in the population who work which is $5.4 \%$ in the data. In our model this implies $\omega=0.12$ and $e=0.0077$ (0.31 years of education). The choice of this alternative measure does not change our conclusions (results available upon request).

${ }^{10}$ The data we use can be found in tables A1.1a, A1.3a and X1.1c. See also the same publication for more detailed information on the educational systems and definitions.
} 
Table 1: Calibration Target for Time in Tertiary Education

\begin{tabular}{|c|c|c|c|c|c|}
\hline & \multicolumn{2}{|c|}{ Graduation Age } & \multicolumn{2}{|c|}{ Share in Population } & Weighted Years \\
\hline Type of Diploma & B & A & $\mathrm{B}$ & $\mathrm{A}$ & $\mathrm{B}+\mathrm{A}$ \\
\hline France & 22.0 & 24.5 & 0.11 & 0.15 & 0.775 \\
\hline Germany & 22.0 & 25.5 & 0.09 & 0.14 & 0.950 \\
\hline Italy & 22.5 & 26.0 & 0.01 & 0.12 & 0.601 \\
\hline
\end{tabular}

Graduation age refers to the average within the particular type of diploma. The country weights (France 0.31 , Germany 0.40 and Italy 0.39 ) are given by the relative population size in 2006 computed from the Human Mortality Database (2008).

these parameters. The graphs have $\omega \in(0,1)$ on the horizontal axis. The different lines are always drawn for a tuple from $\{\xi \otimes s\}$ for selected values for $\xi$ and $s$ where the intermediate values (solid lines) are from the benchmark calibration. Finally, in order to address the sensitivity of our results with respect to the concavity of the education technology we redo all calculations for $\psi=0.3 .{ }^{11}$ We recalibrate the model when we change the value of $\psi$. The vertical black line is the calibrated value of $\omega$. Observe that with lower concavity of the education technology (lower $\psi$ ), the calibrated value of $\omega$ is increased substantially to match the same target. Instead of reporting the rather uninformative numbers for the derivatives, in the figures we show elasticities which are better comparable across calibrations.

The effect of changing survival rates on the capital stock are displayed in figure 1. As claimed in proposition 4, the sign is ambiguous. The sign is more likely to be negative for high survival rates, high marginal productivity of education $(\psi$ and $\xi)$ and high labor market participation in the second period (high $\omega$ ). Obviously, the higher the marginal product of education (as determined by $\xi$ and $\psi$ ), the more will agents invest into education and the less they will work and save. The effect of $\omega$ goes into the same direction since it is reinforcing the effect of education.

Figure 2 shows the elasticity of education with respect to the survival rate. Although we show in proposition 4 that the sign cannot be determined unambiguously, the elasticity is always positive in our simulations. Rising survival rates always increase educational attainment. The simulations also show that the elasticity is smaller for high values of $\xi$ and higher survival rates. The curvature of the human capital production function $\psi$ has only a minor influence.

Finally, figure 3 shows how education varies with the time spent on the labor market in the second period. Although the sign cannot be determined analytically, the simulations show that education always increases if $\omega$ increases. Thus, the direct effect of a rising $\omega$ is not overturned by a general equilibrium effect of rising interest rates. The factor having the largest influence is $\psi$ which governs the shape of the marginal productivity of schooling

\footnotetext{
${ }^{11}$ For the sake of brevity, simulation results with varying $\alpha$ and $\beta$ are not displayed but are available upon request.
} 
Figure 1: Elasticity of $k$ with respect to $s$

(a) Benchmark concavity $(\psi=0.6)$

(i) constant $\tau$

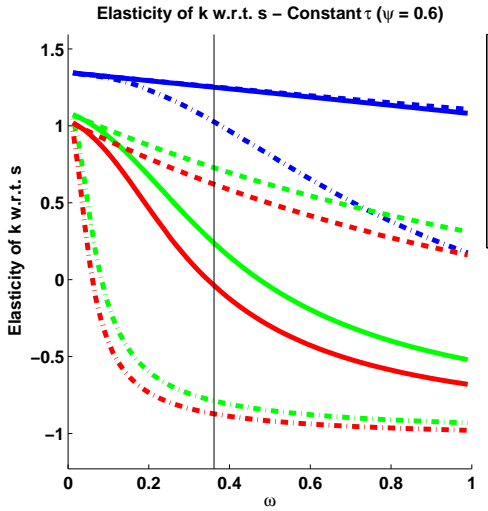

(ii) constant $\rho$

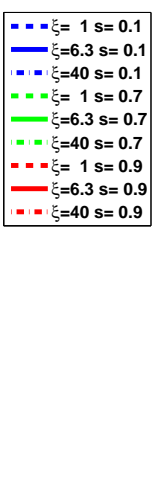

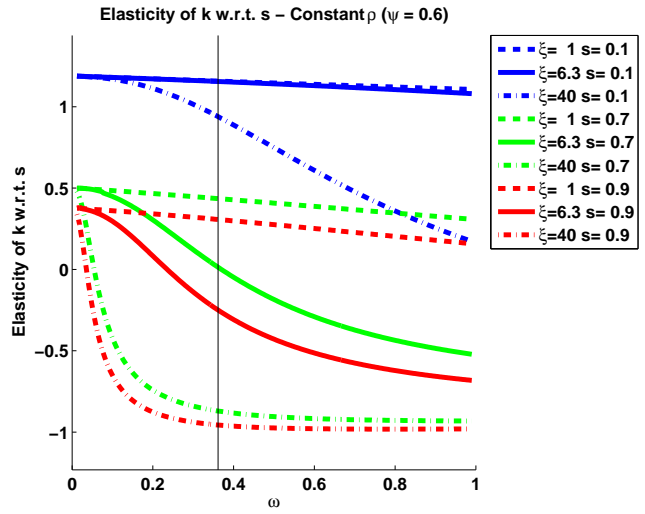

(b) Low concavity $(\psi=0.3)$

(ii) constant $\rho$

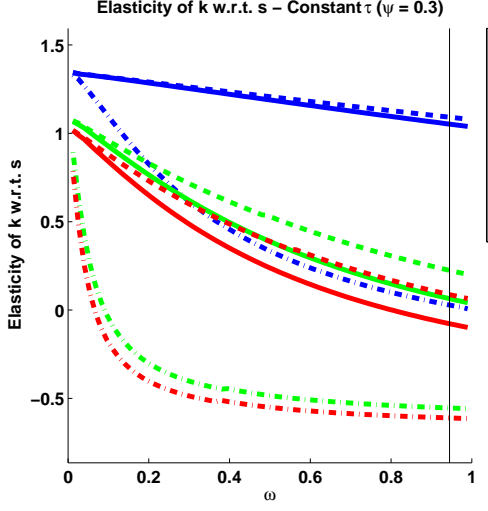

Elasticity of $\mathbf{k}$ w.r.t. $\mathbf{s}-$ Constant $\rho(\psi=0.3)$

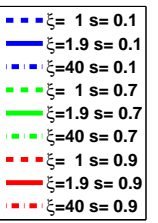

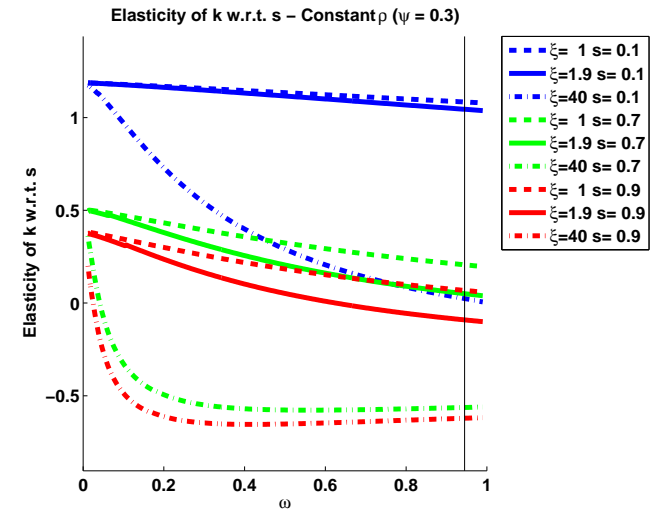


Figure 2: Elasticity of $e$ with respect to $s$

(a) Benchmark concavity $(\psi=0.6)$

(i) constant $\tau$

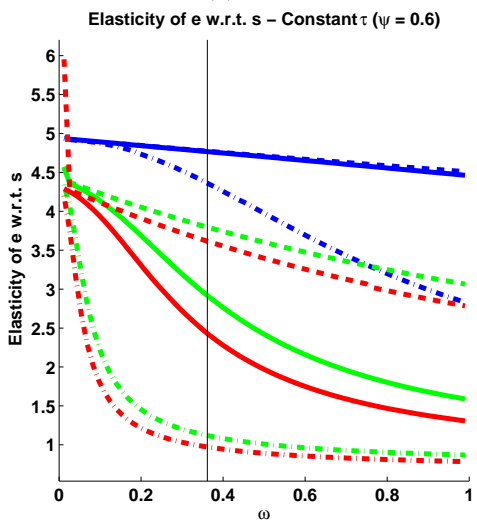

(ii) constant $\rho$

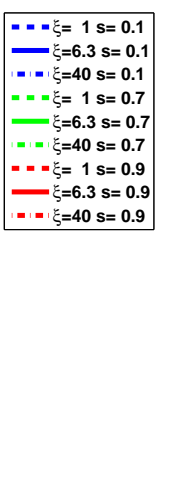

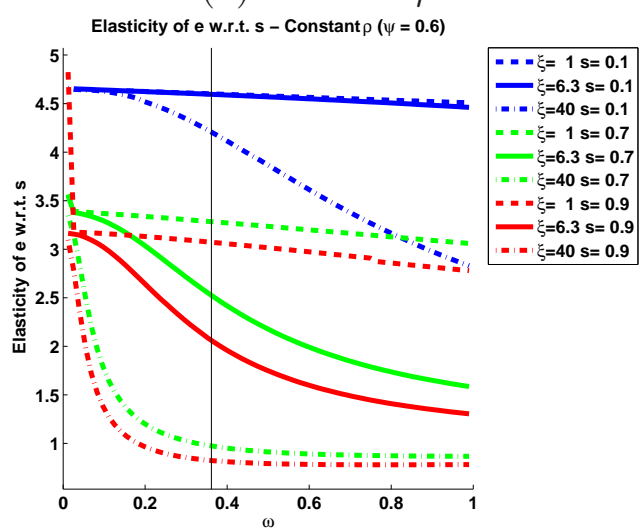

(b) Low concavity $(\psi=0.3)$ (ii) constant $\rho$

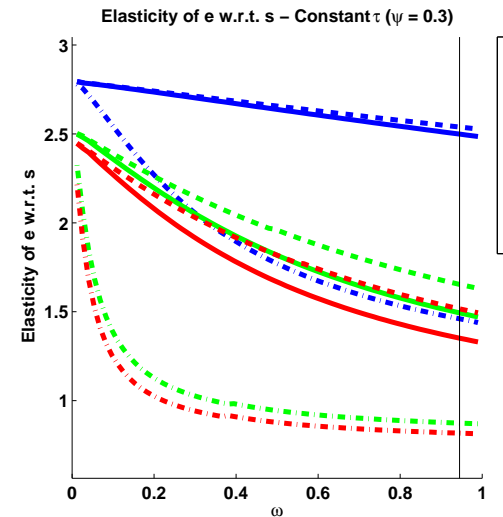

Elasticity of e w.r.t. s - Constant $\rho(\psi=0.3)$
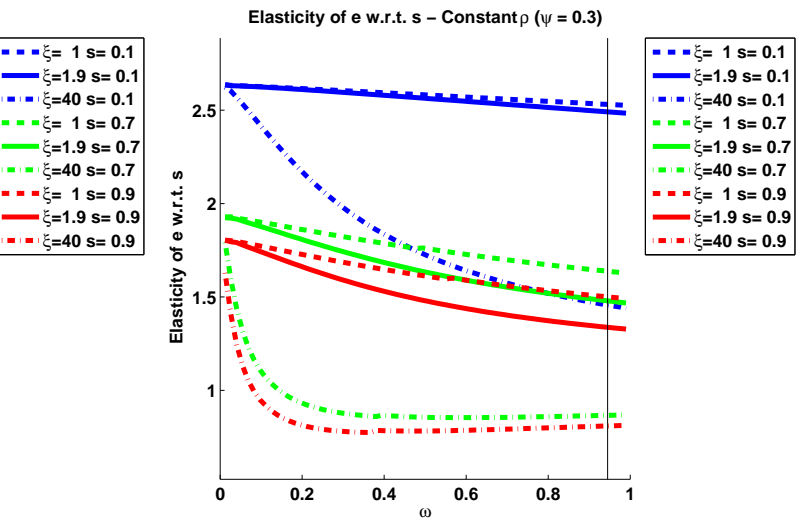
Table 2: Calibration parameters

\begin{tabular}{lcc}
\hline \hline Firm sector & $\psi=0.6$ & $\psi=0.3$ \\
\hline Capital share, $\alpha$ & 0.3 & 0.3 \\
Technological progress, $\gamma^{A}$ & 1.81 & 1.81 \\
\hline Household sector & & \\
\hline Discount factor, $\beta$ & 0.67 & 0.67 \\
Average productivity of human capital investments, $\xi$ & 6.30 & 1.94 \\
Coefficient in human capital production function, $\psi$ & 0.6 & 0.3 \\
Fraction of the old working, $\omega$ & 0.36 & 0.94 \\
\hline Social Security & & \\
\hline Replacement rate, $\varrho$ & 0.6 & 0.6 \\
\hline Demographics & & \\
\hline Birth rate, $\gamma^{N}$ & 1.56 & 1.56 \\
Survival rate, $s$ & 0.69 & 0.69 \\
\hline \hline
\end{tabular}

investment and other parameters seem to have only a small effect on the behavior of the model. Not surprisingly, with more concavity of the human capital production function the (positive) effect of increasing lifetime labor supply on the education decision increases.

\subsubsection{No Annuity Markets}

This subsection provides a sensitivity analysis with respect to changes in the degree of annuitization. We set $\lambda=0$ (corresponding to an economy without annuity markets), recalibrate the model using the same calibration targets as above and report the new parameters in table 3 in the appendix. Since only the partial derivative $\partial k / \partial s$ changes its sign if we vary $\lambda$ we here only show this result in figure 4 . The other figures can be found in appendix B.

Indeed with $\lambda=0$ the reaction of the capital stock to changes in the survival rate is always positive, whereas for $\lambda=1$ it may also be negative. Thus, the degree of completeness of annuity markets has an important effect on the reaction of the economy. The qualitative effects of changes in the population growth rate, $\gamma^{N}$, and lifetime labor supply, $\omega$, are not affected by the choice of $\lambda$ (see appendix B).

\section{Conclusion}

This paper investigates the effects of a changing population structure on capital accumulation and educational investment in a tractable two period model in the spirit of Diamond (1965). We vary the population structure by three dimensions, first, by the fertility rate, second, by the survival rate and, third, by the degree of old-age labor supply. We show 
Figure 3: Elasticity of $e$ with respect to $\omega$

(a) Benchmark concavity $(\psi=0.6)$

(i) constant $\tau$

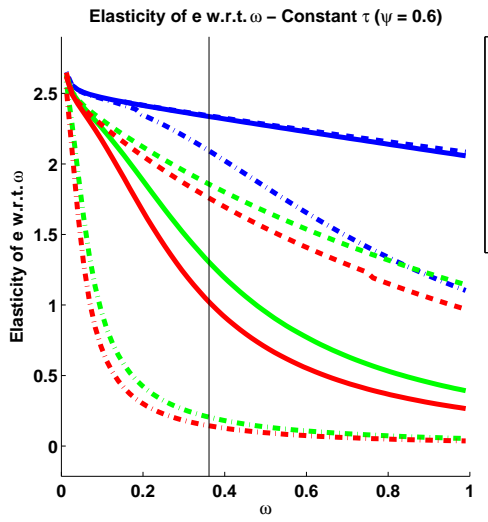

(ii) constant $\rho$

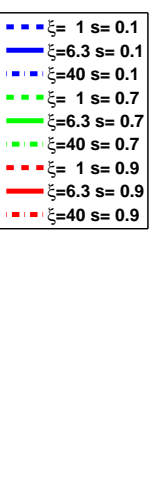

Elasticity of e w.r.t. $\omega$ - Constant $\rho(\psi=0.6)$

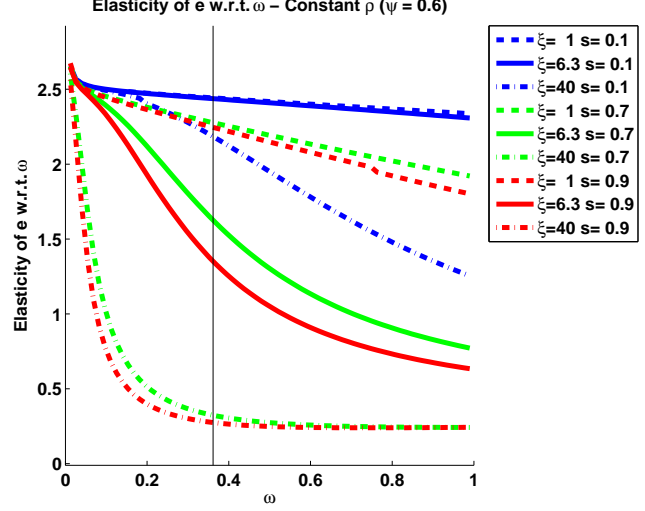

(b) Low concavity $(\psi=0.3)$

(i) constant $\tau$

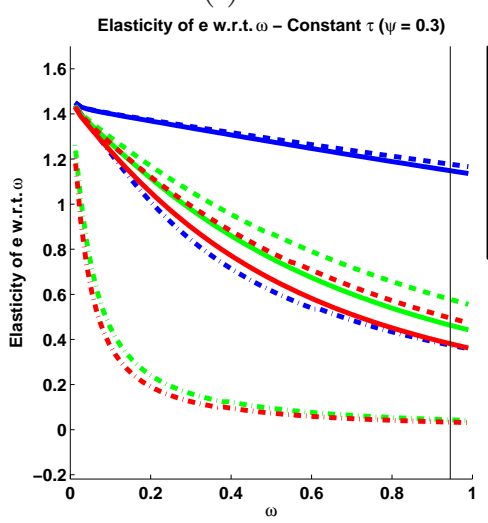

(ii) constant $\rho$

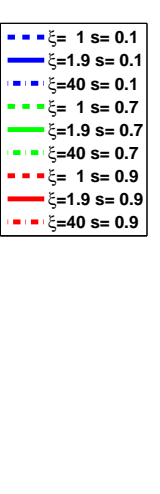

Elasticity of e w.r.t. $\omega$ - Constant $\rho(\psi=0.3)$

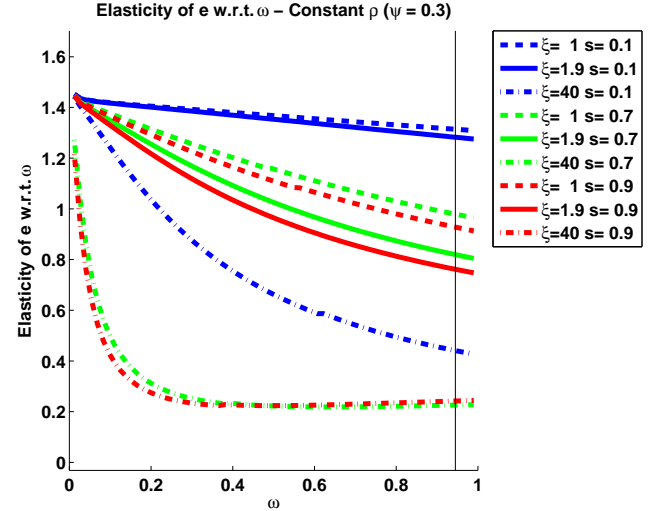


Figure 4: Elasticity of $k$ with respect to $s$ : No Annuity Markets

(a) Benchmark concavity $(\psi=0.6)$

(i) constant $\tau$

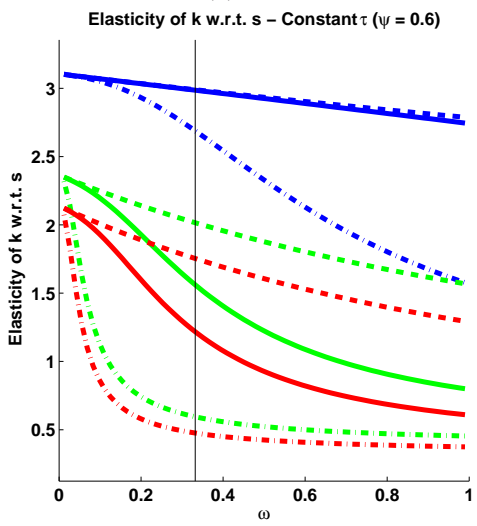

(ii) constant $\rho$

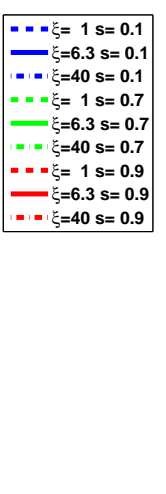

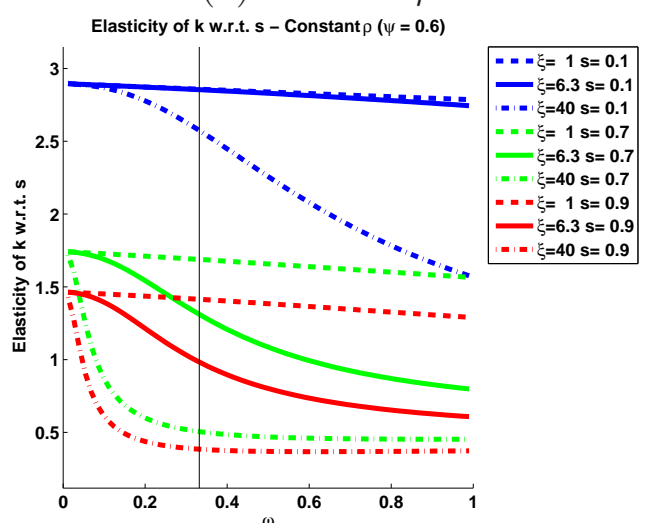

(b) Low concavity $(\psi=0.3)$

(ii) constant $\rho$
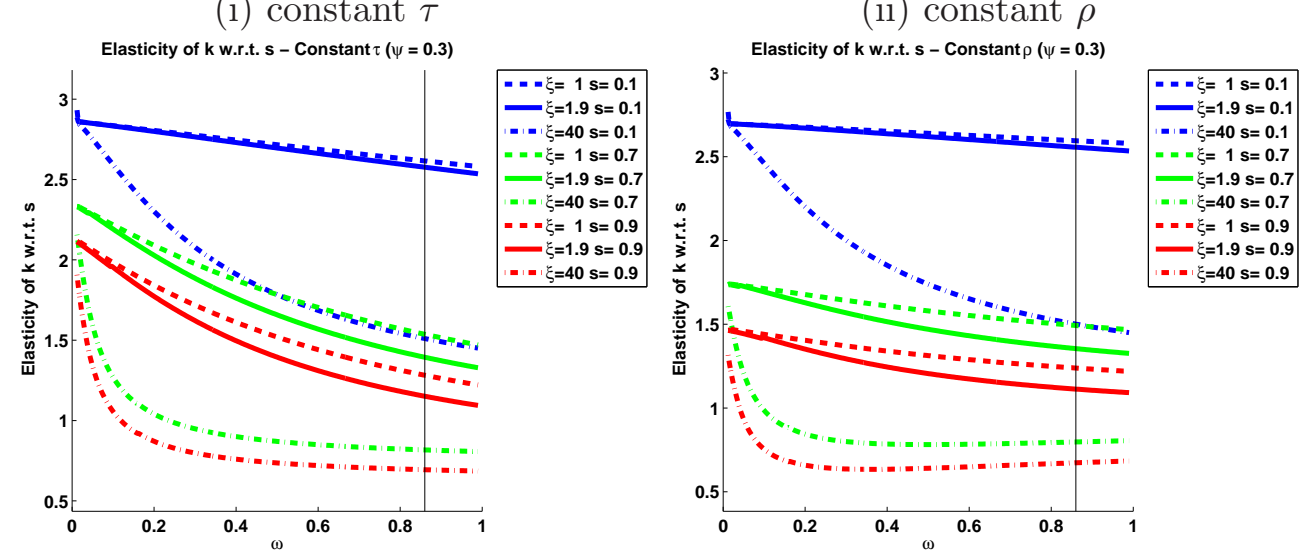
that a decrease of the fertility rate and a corresponding increase of the old-age dependency ratio unambiguously increases the capital intensity and education if contribution rates to the pension system are held constant. An increase of the survival rate, on the other hand, does not unambiguously vary with these variables. Our analytical results and our numerical illustrations shed light on the sources for this ambiguity by highlighting the various and potentially offsetting interaction effects at work. Therefore, our tractable model is a useful laboratory for understanding the magnitudes of the effects found in applied quantitative work employing models with overlapping generations. 


\section{A Proofs}

Proof of proposition 1. We have that

$$
k_{t+1}=\frac{K_{t+1}}{A_{t+1} L_{t+1}}
$$

which, by (22), can be rewritten as

$$
k_{t+1} \frac{L_{t+1}}{N_{t, 0}}=\frac{a_{t, 0}}{A_{t+1}}
$$

We first work on the LHS of (32). Using (23) we get

$$
k_{t+1} \frac{L_{t+1}}{N_{t, 0}}=k_{t+1} h_{0}\left(\left(1-e_{t+1}\right) \gamma_{t+1}^{N}+\omega s_{t+1}\left(1+g\left(e_{t}\right)\right)\right) .
$$

Next, we focus on the RHS of (32). Using (5), (9) and (20) in (14) and bringing the terms involving $a_{t, 0}$ to the LHS of the resulting expression we get

$$
\begin{aligned}
a_{t, 0}\left(1+\frac{\left(1-s_{t+1}\right)(1-\lambda)}{\left(1+\beta s_{t+1}\right) \zeta_{t+1}}\right)= & \frac{h_{0}}{1+\beta s_{t+1}}\left(\beta s_{t+1}\left(1-e_{t}\right)\left(1-\tau_{t}\right) w_{t}-\right. \\
& \left.\frac{w_{t+1}}{\zeta_{t+1}\left(1+r_{t+1}\right)}\left(s_{t+1} \omega\left(1+g\left(e_{t}\right)\right)+\tau_{t+1}\left(1-e_{t+1}\right) \gamma_{t+1}^{N}\right)\right) .
\end{aligned}
$$

Bringing the term postmultiplying $a_{t, 0}$ to the RHS, replacing $r_{t}$ and $w_{t}$ by their marginal products from (18) and dividing by $A_{t+1}$ gives

$$
\begin{aligned}
\frac{a_{t, 0}}{A_{t+1}}=\varphi_{t} \frac{h_{0}}{1+\beta s_{t+1}}\left(\beta s_{t+1}\left(1-e_{t}\right)\left(1-\tau_{t}\right)(1-\alpha) k_{t}^{\alpha} \frac{1}{\gamma^{A}}\right. & \\
& \left.-\frac{1-\alpha}{\alpha \zeta_{t+1}} k_{t+1}\left(s_{t+1} \omega\left(1+g\left(e_{t}\right)\right)+\tau_{t+1}\left(1-e_{t+1}\right) \gamma_{t+1}^{N}\right)\right) .
\end{aligned}
$$

where

$$
\varphi_{t}=\frac{\left(1+\beta s_{t+1}\right) \zeta_{t+1}}{\left(1+\beta s_{t+1}\right) \zeta_{t+1}+\left(1-s_{t+1}\right)(1-\lambda)} .
$$

Next, use the equation above and combine it with (33) to get

$$
\begin{aligned}
& k_{t+1}\left(\left(1-e_{t+1}\right) \gamma_{t+1}^{N}+s_{t+1} \omega\left(1+g\left(e_{t}\right)\right)+\right. \\
& \left.\varphi_{t} \frac{1-\alpha}{\alpha\left(1+\beta s_{t+1}\right) \zeta_{t+1}}\left(s_{t+1} \omega\left(1+g\left(e_{t}\right)\right)+\tau_{t+1}\left(1-e_{t+1}\right) \gamma_{t+1}^{N}\right)\right) \\
& =\varphi_{t} \frac{\beta s_{t+1}(1-\alpha)}{\gamma^{A}\left(1+\beta s_{t+1}\right)}\left(1-e_{t}\right)\left(1-\tau_{t}\right) k_{t}^{\alpha} .
\end{aligned}
$$


Multiply the above by $\alpha\left(1+\beta s_{t+1}\right)$ and simplify to get

$$
\begin{aligned}
k_{t+1}\left(\left(1-e_{t+1}\right) \gamma_{t+1}^{N}\left(\alpha\left(1+\beta s_{t+1}\right)+\varphi_{t} \frac{(1-\alpha) \tau_{t+1}}{\zeta_{t+1}}\right)+\right. & \\
& \left.s_{t+1} \omega\left(1+g\left(e_{t}\right)\right)\left(\alpha\left(1+\beta s_{t+1}\right)+\varphi_{t} \frac{1-\alpha}{\zeta_{t+1}}\right)\right) \\
& =\varphi_{t} \frac{\alpha(1-\alpha) \beta s_{t+1}}{\gamma^{A}}\left(1-e_{t}\right)\left(1-\tau_{t}\right) k_{t}^{\alpha} .
\end{aligned}
$$

The expression for $e_{t}$ immediately follows from replacing wages and interest rates by their respective counterparts from equations (18a) and (18b). Using $\hat{\rho}=\frac{1}{\beta s_{t+1}}-1$ proves the claim in the proposition.

Proof of proposition 2. First, given that the function $g(e)$ satisfies the lower Inada condition with $\lim _{e \rightarrow 0} g^{\prime}(e) \rightarrow \infty$ the solution with zero education is excluded for $\omega \in(0,1]$. Second, having full educational investment (i.e. $e=1$ ), labor supply and thus wage income of the young generation is zero. By the lower Inada condition of the utility function, we have that $c_{t, 0}>0$ for positive wages. Consequently, savings in the first period would be negative and so will be the capital stock of the economy. Thus, if there is an equilibrium with finite and positive capital stock, education will always be lower than unity.

To show that education always converges to the steady state solution use (24a) in (24b) and rewrite the resulting expression as

$$
e_{t}^{1-\psi}=\frac{s_{t+1}}{\zeta_{t+1}} \omega \xi \psi \frac{(1-\alpha)\left(1-\tau_{t+1}\right)}{\left(\Gamma_{1} \frac{1-e_{t+1}}{1-e_{t}}+\Gamma_{2} \frac{1+g\left(e_{t}\right)}{1-e_{t}}\right)}
$$

where

$$
\begin{aligned}
\Gamma_{1} & \equiv\left(\alpha\left(2+\hat{\rho}_{t+1}\right)+\varphi_{t} \frac{(1-\alpha) \tau_{t+1}}{\zeta_{t+1}}\left(1+\hat{\rho}_{t+1}\right)\right) \gamma_{t+1}^{N} \\
\Gamma_{2} & \equiv \omega s_{t+1}\left(\alpha\left(2+\hat{\rho}_{t+1}\right)+\varphi_{t} \frac{1-\alpha}{\zeta_{t+1}}\left(1+\hat{\rho}_{t+1}\right)\right)
\end{aligned}
$$

Defining $\Delta_{t} \equiv e_{t}-e_{t+1}\left(k^{*}\right)$ as measuring the distance between $e_{t}$ and $e_{t+1}$ which is ultimately a function of the steady state capital stock. Thus, $\Delta_{t}$ measures the change in education between $t$ and $t+1$ outside the steady state. Rearranging gives

$$
F\left(e_{t}, \Delta_{t}\right)=e_{t}^{1-\psi}-\frac{s_{t+1}}{\zeta_{t+1}} \omega \xi \psi \frac{(1-\alpha)\left(1-\tau_{t+1}\right)}{\left(\Gamma_{1} \frac{1-e_{t}+\Delta_{t}}{1-e_{t}}+\Gamma_{2} \frac{1+g\left(e_{t}\right)}{1-e_{t}}\right)} .
$$

Taking the derivative of $e_{t}$ with respect to the distance to the steady state gives

$$
\begin{aligned}
\frac{\partial e_{t}}{\partial \Delta_{t}} & =-\frac{\partial F / \partial \Delta_{t}}{\partial F / \partial e_{t}}<0 \\
\frac{\partial^{2} e_{t}}{\partial \Delta_{t}^{2}} & >0 .
\end{aligned}
$$


Therefore, if education is, e.g., below its new steady state level after an exogenous shock (i.e., $\Delta_{t}<0$ ), $e_{t}$ will always converge monotonically to the new steady state value.

Proof of proposition 3. Existence:

Using equation (22) and the assumption of constant population growth we have

$$
k_{t+1}=\frac{1}{\gamma^{N} \gamma^{A}} \tilde{a}_{t, 0}
$$

where $\tilde{a}_{t, 0}$ is equation (22) divided by $A_{t}$ to transform $a_{t, 0}$ into savings per efficient worker. Define the function

$$
d\left(w_{t}, r_{t+1}\right)=\gamma^{A} \gamma^{N} k_{t+1}-\tilde{a}\left(w_{t}\left(k_{t}\right), r_{t+1}\left(k_{t+1}\right), e_{t}\left(k_{t+1}\right)\right) .
$$

Where $d(\cdot)$ is the change in the capital stock per effective worker. Given that we use $\log$-utility, $e_{t} \in(0,1)$ and a Cobb-Douglas production function it holds that

$$
\begin{aligned}
& 0<\tilde{a}\left(w_{t}, r_{t+1}, e_{t}\right)<\tilde{w}_{t}, \\
& 0<\frac{\tilde{a}\left(w_{t}, r_{t+1}, e_{t}\right)}{k_{t+1}}<\frac{\tilde{w}_{t}}{k_{t+1}} .
\end{aligned}
$$

where $\tilde{w}_{t}$ denotes wages scaled by the level of technology. All we have to show is that $d(\cdot)$ has opposite signs for $k_{t+1}$ going to zero and infinity. Then by continuity of $d(\cdot)$ there is at least one capital stock satisfying $d(\cdot)=0$. This holds since

$$
\frac{d\left(w_{t}, r_{t+1}\right)}{k_{t+1}}=\gamma^{N} \gamma^{A}-\frac{\tilde{a}\left(w_{t}, r_{t+1}, e_{t}\right)}{k_{t+1}}
$$

and taking the limits gives

$$
\begin{aligned}
& \lim _{k_{t+1} \rightarrow \infty} \frac{d\left(w_{t}, r_{t+1}\right)}{k_{t+1}}=\gamma^{N} \gamma^{A}>0 \\
& \lim _{k_{t+1} \rightarrow 0} \frac{d\left(w_{t}, r_{t+1}\right)}{k_{t+1}}=-\infty<0
\end{aligned}
$$

for sufficiently small $k_{t+1}$. For uniqueness it is sufficient to show that $\partial d\left(w_{t}, r_{t+1}\right) / \partial k_{t+1}>0$ for all $k$, i.e. that for a given wage rate $d\left(w_{t}, r_{t+1}\right)$ is nondecreasing in the capital stock. Taking equation (25a) and recalling that $\partial e / \partial k>0$ establishes the result. By using equation (26b) it is clear that a unique solution for the capital stock automatically gives a unique $e$. 
Proof of proposition 4. From (26) define

$$
\begin{aligned}
& F_{1}\left(k, e ; \gamma^{N}, s, \lambda, \omega\right)=\Omega\left(e, \gamma^{N}, s, \lambda, \omega\right)^{\frac{1}{1-\alpha}}-k=0 \\
& F_{2}\left(k, e ; \gamma^{N}, s, \lambda, \omega\right)=c \cdot\left(\frac{s}{\zeta}\right)^{\frac{1}{1-\psi}} \cdot k^{\frac{1-\alpha}{1-\psi}}-e=0
\end{aligned}
$$

where

$$
\begin{aligned}
\Omega\left(e, \gamma^{N}, s, \lambda, \omega\right) & \equiv \frac{\varphi}{\phi}(1-\tau) \alpha(1-\alpha) \beta \\
c & \equiv\left[\omega \xi \psi \frac{\gamma^{A}}{\alpha}\right]^{\frac{1}{1-\psi}}
\end{aligned}
$$

and $\phi$ is as in (27a) and $\varphi$ as in (27b).

1. For the case where $\tau=\bar{\tau}$, we can ignore that $\tau$ is related to $\gamma^{N}$ and $s$ by the steady state version of (21). The general problem with two implicitly defined endogenous variables can be written as

$$
\left[\begin{array}{l}
\frac{\partial k}{\partial X} \\
\frac{\partial e}{\partial X}
\end{array}\right]=-\left[\begin{array}{ll}
\frac{\partial F_{1}}{\partial k} & \frac{\partial F_{1}}{\partial e} \\
\frac{\partial F_{2}}{\partial k} & \frac{\partial F_{2}}{\partial e}
\end{array}\right]^{-1}\left[\begin{array}{l}
\frac{\partial F_{1}}{\partial X} \\
\frac{\partial F_{2}}{\partial X}
\end{array}\right]=-A^{-1}\left[\begin{array}{l}
\frac{\partial F_{1}}{\partial X} \\
\frac{\partial F_{2}}{\partial X}
\end{array}\right]
$$

where $X$ is any variable from the vector of exogenous variables $\left\{\gamma_{N}, s, \omega,\right\}$ and therefore

$$
\left[\begin{array}{l}
\frac{\partial k}{\partial X} \\
\frac{\partial e}{\partial X}
\end{array}\right]=-|A|^{-1}\left[\begin{array}{cc}
\frac{\partial F_{2}}{\partial e} & -\frac{\partial F_{1}}{\partial e} \\
-\frac{\partial F_{2}}{\partial k} & \frac{\partial F_{1}}{\partial k}
\end{array}\right]\left[\begin{array}{l}
\frac{\partial F_{1}}{\partial X} \\
\frac{\partial F_{2}}{\partial X}
\end{array}\right]
$$

and rearranging gives

$$
\left[\begin{array}{l}
\frac{\partial k}{\partial X} \\
\frac{\partial e}{\partial X}
\end{array}\right]=-|A|^{-1}\left[\begin{array}{cc}
\frac{\partial F_{2}}{\partial e} \frac{\partial F_{1}}{\partial X} & -\frac{\partial F_{1}}{\partial e} \frac{\partial F_{2}}{\partial X} \\
-\frac{\partial F_{2}}{\partial k} \frac{\partial F_{1}}{\partial X} & +\frac{\partial F_{1}}{\partial k} \frac{\partial F_{2}}{\partial X}
\end{array}\right]
$$

Since $\tau=\bar{\tau}$, we get

$$
\begin{aligned}
& \frac{\partial F_{1}}{\partial k}=-1<0 \\
& \frac{\partial F_{1}}{\partial e}=\frac{1}{1-\alpha} \Omega^{1 /(1-\alpha)-1} \frac{\partial \Omega}{\partial e}<0 \\
& \frac{\partial F_{2}}{\partial k}=c\left(\frac{s}{\zeta}\right)^{\frac{1}{1-\psi}} \frac{1-\alpha}{1-\psi} k^{\frac{1-\alpha}{1-\psi}-1}>0 \\
& \frac{\partial F_{2}}{\partial e}=-1<0
\end{aligned}
$$

whereby the sign in (45b) follows from $\frac{\partial \Omega}{\partial e}<0$. Consequently,

$$
|A|=\underbrace{\frac{\partial F_{1}}{\partial k} \frac{\partial F_{2}}{\partial e}}_{=1}-\underbrace{\frac{\partial F_{1}}{\partial e} \frac{\partial F_{2}}{\partial k}}_{<0}>0 .
$$


(a) To determine the effect of a changing population growth rate $\gamma_{N}$ on $k$ and $e$ we have to replace $X$ by $\gamma_{N}$ in equation (42) which gives

$$
\begin{aligned}
& \frac{\partial F_{1}}{\partial \gamma^{N}}=\frac{1}{1-\alpha} \Omega^{1 /(1-\alpha)-1} \frac{\partial \Omega}{\partial \gamma^{N}}<0 \\
& \frac{\partial F_{2}}{\partial \gamma^{N}}=0
\end{aligned}
$$

whereby (47a) follows from $\frac{\partial \Omega}{\partial \gamma^{N}}<0$, cf. equations (40) and (27a). To get an intuitive idea what is determining the sign, note that we can write

$$
\frac{\partial \Omega}{\partial \gamma^{N}}=\frac{\partial \varphi / \partial \gamma^{N} \phi-\varphi \partial \phi / \partial \gamma^{N}}{\phi^{2}}=-\frac{\varphi \partial \phi / \partial \gamma^{N}}{\phi^{2}}<0
$$

since $\varphi$ is independent of $\gamma^{N}$ and $\phi$ is a positive function of $\gamma^{N}$, cf. equations (26a) and (27). Thus, $\gamma^{N}$ has a direct effect on $k$ but only an indirect effect on $e$ via changing relative prices (this is the reason why $\partial F_{2} / \partial \gamma^{N}=0$ ). Formally, we have

$$
\begin{gathered}
\frac{\partial k}{\partial \gamma^{N}}=-|A|^{-1}(\underbrace{\frac{\partial F_{2}}{\partial e} \frac{\partial F_{1}}{\partial \gamma^{N}}}_{>0}-\underbrace{\frac{\partial F_{1}}{\partial e} \frac{\partial F_{2}}{\partial \gamma^{N}}}_{=0})<0 \\
\frac{\partial e}{\partial \gamma^{N}}=-|A|^{-1}(-\underbrace{\frac{\partial F_{2}}{\partial k} \frac{\partial F_{1}}{\partial \gamma^{N}}}_{<0}+\underbrace{\frac{\partial F_{1}}{\partial k} \frac{\partial F_{2}}{\partial \gamma^{N}}}_{=0})<0 .
\end{gathered}
$$

(b) To derive the analogous steps for differentiation of (39) with respect to $s$, replace the terms in (47) by

$$
\begin{aligned}
\frac{\partial F_{1}}{\partial s} & =\frac{1}{1-\alpha} \Omega^{1 /(1-\alpha)-1} \frac{\partial \Omega}{\partial s} \gtrless 0 \\
\frac{\partial F_{2}}{\partial s} & =c k^{\frac{1-\alpha}{1-\psi}} \frac{\partial \frac{s}{\zeta}}{\partial s} \geq 0 .
\end{aligned}
$$

giving

$$
\begin{aligned}
& \frac{\partial k}{\partial s}=-|A|^{-1}(\underbrace{\frac{\partial F_{2}}{\partial e} \frac{\partial F_{1}}{\partial s}}_{\gtrless 0}-\underbrace{\frac{\partial F_{1}}{\partial e} \frac{\partial F_{2}}{\partial s}}_{\leq 0}) \gtrless 0 \\
& \frac{\partial e}{\partial s}=-|A|^{-1}(-\underbrace{\frac{\partial F_{2}}{\partial k} \frac{\partial F_{1}}{\partial s}}_{\gtrless 0}+\underbrace{\frac{\partial F_{1}}{\partial k} \frac{\partial F_{2}}{\partial s}}_{\leq 0}) \gtrless 0 .
\end{aligned}
$$


Intuitively, the ambiguity of $\frac{\partial e}{\partial s}$ results from the fact that, holding $k$ constant, $e$ is increasing in $s$ as long as $\lambda>0$ (direct effect), but the capital stock may increase or decrease in $s$ for given education $e$. As $e$ increases in $k$ monotonically, the ambiguity of $\frac{\partial k}{\partial s}$ translates into the ambiguity of $\frac{\partial e}{\partial s}$ (indirect effect of $s$ on e).

Arguing formally, the ambiguity of $\frac{\partial k}{\partial s}$ comes from

$$
\frac{\partial \Omega}{\partial s}=\frac{\partial(\varphi / \phi)}{\partial s}=\alpha(1-\alpha) \beta(1-\tau) \frac{\varphi^{\prime} \phi-\varphi \phi^{\prime}}{\phi^{2}} \gtrless 0
$$

where $\phi^{\prime}=\partial \phi / \partial s$ and $\varphi^{\prime}=\partial \varphi / \partial s$, cf. equation (26a). It can be shown that $\varphi^{\prime}>0$. Consequently, the sign of $\frac{\partial \phi}{\partial s}$ determines the sign of $\frac{\partial F_{1}}{\partial s}$ (and thus $\frac{\partial \Omega}{\partial s}$ ) and therefore the sign of equation (50a) is unambiguous only if $\frac{\partial \phi}{\partial s}<0$.

To see what determines the sign of $\phi^{\prime}$, observe from (27a) that $s$ enters in three places: (i) $s$ pre-multiplies the term $\omega \frac{1+g(e)}{1-e}$, (ii) $s$ decreases the effective discount rate $\hat{\rho}$, and (iii) $s$ increases the annuity factor, $\zeta$, as long as $\lambda<1$. Consequently, $\phi$ increases in $s$ by effect (i) whereas it decreases in $s$ by the effects (ii) and (iii). We can therefore study an upper bound of $\phi^{\prime}$ by setting $\lambda=1$ so that effect (iii) is not at work.

This helps clarifying the interaction at the cost of introducing a special case. Using $\hat{\rho}=\frac{1}{\beta s}-1$ in (27a) and taking the derivative of the resulting equation with respect to $s$, gives

$$
\frac{\partial \phi}{\partial s} \frac{1}{\gamma_{A}}=\omega \alpha \frac{1+g(e)}{1-e}-\frac{\gamma^{N}}{s^{2} \beta}[1-(1-\alpha)(1-\tau)] \gtrless 0,
$$

which is ambiguous. ${ }^{12}$ The right part of this equation consists only of exogenous variables. The left part involves the endogenous education decision $e$ for which no closed form solution is available. Thus, it is not possible to show analytically that the derivative has an unambiguous sign. However, constructing a few special cases clarifies under which conditions $\frac{\partial \phi}{\partial s}<0$ may hold.

- For $\omega \rightarrow 0$ the left part converges to zero ( $e$ also converges to zero) and thus $\frac{\partial \phi}{\partial s}<0$.

- For $\omega=1$, which implies that $\tau=0$, we have

$$
\frac{\partial \phi}{\partial s} \frac{1}{\gamma_{A}}=\alpha\left(\frac{1+g(e)}{1-e}-\frac{\gamma^{N}}{s^{2} \beta}\right) \gtrless 0 .
$$

${ }^{12}$ To see what happens for $\lambda \neq 1$ define $\mu \equiv \varphi / \xi$ and $\mu^{\prime} \equiv \partial \mu / \partial s$. Then the corresponding term is

$$
\frac{\partial \phi}{\partial s} \frac{1}{\gamma^{A}}=\omega \frac{1+g e(e)}{1-e}\left(\alpha+\mu^{\prime} \frac{1-\alpha}{\beta}\right)-\frac{\gamma^{N}}{s^{2} \beta}(\alpha+(1-\alpha) \mu \tau)+\mu^{\prime} \frac{\gamma^{N}(1-\alpha) \tau}{s \beta}
$$

where it is obvious that the last two terms are negative $\left(\mu>0\right.$ and $\left.\mu^{\prime}<0\right)$ but the sign of term in the first bracket is ambiguous again. Thus, by setting $\lambda=1$ (perfect annuity markets) which implies $\frac{\varphi}{\zeta}=1$ we know that $\left.\phi^{\prime}\right|_{0 \leq \lambda<1}<\left.\phi^{\prime}\right|_{\lambda=1}$ holds. 
- For $\xi \rightarrow 0$ or $\psi \rightarrow 0$ we have that $e \rightarrow 0$ which means that

$$
\frac{\partial \phi}{\partial s} \frac{1}{\gamma_{A}}=\omega \alpha-\frac{\gamma^{N}}{s^{2} \beta}[1-(1-\alpha)(1-\tau)] \gtrless 0 .
$$

Summarizing the arguments made so far, the sign of $\frac{\partial \phi}{\partial s}$ is negative (implying that $k$ is increasing in $s$ ) if

- returns to education are low (low $\xi$ and/or $\psi$ )

- the horizon over which the benefits can be reaped is short (low $\omega$ )

- the discount factor $\beta$ is low (i.e. high discount rate)

- the population growth rate $\gamma^{N}$ is high

- and the survival probability $s$ is low.

(c) Changing the planning horizon $\omega$ gives

$$
\begin{aligned}
& \frac{\partial F_{1}}{\partial \omega}=\frac{\partial \Omega}{\partial \omega}<0 \\
& \frac{\partial F_{2}}{\partial \omega}=\frac{1}{1-\psi} \omega^{\frac{\psi}{1-\psi}}\left(\xi \psi \frac{\gamma^{A}}{\alpha}\right)^{\frac{1}{1-\psi}}\left(\frac{s}{\zeta}\right)^{\frac{1}{1-\psi}} k^{\frac{1-\alpha}{1-\psi}}>0 .
\end{aligned}
$$

and therefore

$$
\begin{aligned}
& \frac{\partial k}{\partial \omega}=-|A|^{-1}(\underbrace{\frac{\partial F_{2}}{\partial e} \frac{\partial F_{1}}{\partial \omega}}_{>0}-\underbrace{\frac{\partial F_{1}}{\partial e} \frac{\partial F_{2}}{\partial \omega}}_{<0})<0 \\
& \frac{\partial e}{\partial \omega}=-|A|^{-1}(-\underbrace{\frac{\partial F_{2}}{\partial k} \frac{\partial F_{1}}{\partial \omega}}_{<0}+\underbrace{\frac{\partial F_{1}}{\partial k} \frac{\partial F_{2}}{\partial \omega}}_{<0}) \gtrless 0 .
\end{aligned}
$$

Some intuition why the sign of $\partial e / \partial \omega$ is indeterminate can be gained by writing out (54b) and inserting the derivatives from above which gives

$$
\frac{\partial e}{\partial \omega}=|A|^{-1}\left(\frac{s}{\zeta}\right)^{\frac{1}{1-\psi}} \frac{k^{\frac{1-\alpha}{1-\psi}}}{1-\psi}\left((1-\alpha) \frac{\partial \Omega}{\partial \omega} k^{-1}+\omega^{-1}\right) .
$$

Hence, the ambiguity is caused by the negative effect of rising labor market participation on the capital stock $(\partial \Omega / \partial \omega<0)$ and the positive counterbalancing effect of more education $\left(\omega^{-1}\right)$ due to a higher lifetime labor supply $\omega$.

On the contrary, the reason why the sign of $\partial k / \partial \omega$ can always be determined is that the effect of $\omega$ on $k$ and $e$ work into the same direction. Writing out (54a) and simplifying yields

$$
\frac{\partial k}{\partial \omega}=|A|^{-1}\left(\frac{\partial \Omega}{\partial \omega}-\frac{1}{1-\psi} \omega^{-1} e\right)<0
$$

where $\partial \Omega / \partial \omega<0$ captures the direct effect of more labor and the second part captures the additional effect of changing education. 
2. In case $\varrho=\bar{\varrho}$, there is a direct (d) and an indirect effect in the partial derivatives of $\Omega, \frac{\partial \Omega}{\partial X}=\left(\frac{\partial \Omega}{\partial X}\right)^{d}+\frac{\partial \Omega}{\partial \tau} \frac{\partial \tau}{\partial X}$. Observe from (21) that

$$
\begin{aligned}
\frac{\partial \tau}{\partial s} & =\frac{\gamma^{N} \bar{\rho}(1-\omega)}{\left(s(\bar{\rho}(1-\omega)+\omega)+\gamma^{N}\right)^{2}}>0 \\
\frac{\partial \tau}{\partial \gamma^{N}} & =-\frac{s \bar{\rho}(1-\omega)}{\left(s(\bar{\rho}(1-\omega)+\omega)+\gamma^{N}\right)^{2}}<0 \\
\frac{\partial \tau}{\partial \omega} & =-\frac{s \bar{\rho}\left(s+\gamma^{N}\right)}{\left(s(\bar{\rho}(1-\omega)+\omega)+\gamma^{N}\right)^{2}}<0
\end{aligned}
$$

Therefore, for given $\gamma^{N}, s$, and $\omega$, the strength of the indirect effect increases in $\bar{\varrho}$. Note that changing the adjustment rule of the social security system affects only $F_{1}$ because there is no direct effect of $\tau$ on the education decision in steady state. Due to the additional indirect effect, it is not possible any more to determine the sign of the derivatives. We can only say, whether the effects become smaller or larger, compared to the $\tau=\bar{\tau}$ case.

(a) The difference between the two social security scenarios if $\gamma^{N}$ changes and $\tau$ adjusts is given by

$$
\frac{\partial F_{1}}{\partial \gamma^{N}}=\Omega^{1 /(1-\alpha)-1} \alpha \beta\left(\frac{\partial \varphi / \phi}{\partial \gamma^{N}}(1-\tau)-\frac{\varphi}{\phi} \frac{\partial \tau}{\partial \gamma^{N}}\right)
$$

with

$$
\frac{\partial \phi}{\partial \gamma^{N}}=\gamma^{A}\left(\alpha(2+\hat{\rho})+\varphi \frac{(1-\alpha)}{\zeta}(1+\hat{\rho})\left(\tau+\gamma^{N} \frac{\partial \tau}{\partial \gamma^{N}}\right)\right)>0
$$

where the difference to the $\tau=\bar{\tau}$ scenario is only the term $\gamma^{N} \frac{\partial \tau}{\partial \gamma^{N}}$. Using equation (56) implies that

$$
\left.\frac{\partial F_{1}}{\partial \gamma^{N}}\right|_{\rho=\bar{\rho}}>\left.\frac{\partial F_{1}}{\partial \gamma^{N}}\right|_{\tau=\bar{\tau}}
$$

which proves that

$$
\left.\frac{\partial k}{\partial \gamma^{N}}\right|_{\varrho=\bar{\varrho}}>\left.\frac{\partial k}{\partial \gamma^{N}}\right|_{\tau=\bar{\tau}} \text { and }\left.\frac{\partial e}{\partial \gamma^{N}}\right|_{\varrho=\bar{\varrho}}>\left.\frac{\partial e}{\partial \gamma^{N}}\right|_{\tau=\bar{\tau}} .
$$

(b) To see how changes in the survival rate affect $k$ and $e$ with fixed replacement rate we have to evaluate

$$
\frac{\partial F_{1}}{\partial s}=\Omega^{1 /(1-\alpha)-1} \beta \alpha\left(\frac{\partial \varphi / \phi}{\partial s}(1-\tau)-\frac{\varphi}{\phi} \frac{\partial \tau}{\partial s}\right) .
$$

The right part in the parentheses is obviously negative. To obtain the total effect we have to evaluate $\frac{\partial(\varphi / \phi)}{\partial s}$. Since $\varphi$ does not vary with $\tau$, there is no 
indirect effect. Thus we again only have to evaluate the change in $\phi$ including now the change in the contribution rate $\tau$. Again differentiating (27a) with respect to $s$ gives

$$
\frac{\partial \phi}{\partial s} \frac{1}{\gamma_{A}}=\omega \alpha \frac{1+g(e)}{1-e}-\frac{\gamma^{N}}{s^{2} \beta}[1-(1-\alpha)(1-\tau)]+(1-\alpha) \frac{\gamma^{N}}{s \beta} \frac{\partial \tau}{\partial s}<0
$$

where we see that the derivative is identical to the case with $\tau=\bar{\tau}$ except for the last positive term. Using (52) and knowing that $\partial \phi / \partial s$ evaluated with the indirect effect is larger (smaller in absolute value) gives

$$
\left.\frac{\partial \varphi / \phi}{\partial s}\right|_{\rho=\bar{\rho}}<\left.\left.\frac{\partial \varphi / \phi}{\partial s}\right|_{\tau=\bar{\tau}} \Rightarrow \frac{\partial F_{1}}{\partial s}\right|_{\rho=\bar{\rho}}<\left.\frac{\partial F_{1}}{\partial s}\right|_{\tau=\bar{\tau}}
$$

which implies that

$$
\left.\frac{\partial k}{\partial s}\right|_{\varrho=\bar{\varrho}}<\left.\frac{\partial k}{\partial s}\right|_{\tau=\bar{\tau}} \text { and }\left.\frac{\partial e}{\partial s}\right|_{\varrho=\bar{\varrho}}<\left.\frac{\partial e}{\partial s}\right|_{\tau=\bar{\tau}} .
$$

(c) Differences between the two social security scenarios if $\omega$ changes are given by

$$
\frac{\partial F_{1}}{\partial \omega}=\Omega^{1 /(1-\alpha)-1} \beta \alpha\left(\frac{\partial \varphi / \phi}{\partial \omega}(1-\tau)-\frac{\varphi}{\phi} \frac{\partial \tau}{\partial \omega}\right) .
$$

Differentiating equation (27a) with respect to $\omega$ gives

$$
\begin{aligned}
\frac{\partial \phi}{\partial \omega}=\gamma^{A}\left(\varphi \frac{(1-\alpha)}{\zeta}(1+\hat{\rho})\right. & \gamma^{N} \frac{\partial \tau}{\partial \omega} \\
& \left.+s\left(\alpha(2+\hat{\rho})+\varphi \frac{1-\alpha}{\zeta}(1+\hat{\rho})\right) \frac{1+g(e)}{1-e}\right),
\end{aligned}
$$

where the difference being only the adjusting contribution rate $\frac{\partial \tau}{\partial \omega}$. Using equation (57) it holds that

$$
\left.\frac{\partial F_{1}}{\partial \omega}\right|_{\rho=\bar{\rho}}>\left.\frac{\partial F_{1}}{\partial \omega}\right|_{\tau=\bar{\tau}}
$$

proving that

$$
\left.\frac{\partial k}{\partial \omega}\right|_{\varrho=\bar{\varrho}}>\left.\frac{\partial k}{\partial \omega}\right|_{\tau=\bar{\tau}} \text { and }\left.\frac{\partial e}{\partial \omega}\right|_{\varrho=\bar{\varrho}}>\left.\frac{\partial e}{\partial \omega}\right|_{\tau=\bar{\tau}} .
$$


Proof of proposition 5. The effect of the degree of annuitization $(\lambda)$ on the capital stock and education decision is given by

$$
\begin{aligned}
& \frac{\partial F_{1}}{\partial \lambda}=\frac{\partial \Omega}{\partial \lambda}>0 \\
& \frac{\partial F_{2}}{\partial \lambda}=c \cdot s^{\frac{1}{1-\psi}} k^{\frac{1-\alpha}{1-\psi}} \frac{\partial \zeta^{-1}}{\partial \lambda}<0 .
\end{aligned}
$$

Replacing the terms in (47) by the ones from above gives

$$
\begin{aligned}
& \frac{\partial k}{\partial \lambda}=-|A|^{-1}(\underbrace{\frac{\partial F_{2}}{\partial e} \frac{\partial F_{1}}{\partial \lambda}}_{<0}-\underbrace{\frac{\partial F_{1}}{\partial e} \frac{\partial F_{2}}{\partial \lambda}}_{>0})>0 \\
& \frac{\partial e}{\partial \lambda}=-|A|^{-1}(-\underbrace{\frac{\partial F_{2}}{\partial k} \frac{\partial F_{1}}{\partial \lambda}}_{>0}+\underbrace{\frac{\partial F_{1}}{\partial k} \frac{\partial F_{2}}{\partial \lambda}}_{>0}) \gtrless 0
\end{aligned}
$$

Qualitatively, changing $\lambda$ has the same effects in both social security scenarios because the availability of annuity markets does not interact with the adjustment of contribution or replacement rates. 


\section{B Numerical Results: No Annuity Markets}

Table 3: Calibration parameters: No Annuity Markets

\begin{tabular}{lcc}
\hline \hline Firm sector & $\psi=0.6$ & $\psi=0.3$ \\
\hline Capital share, $\alpha$ & 0.3 & 0.3 \\
Technological progress, $\gamma^{A}$ & 1.81 & 1.81 \\
\hline Household sector & & \\
\hline Discount factor, $\beta$ & 0.67 & 0.67 \\
Average productivity of human capital investments, $\xi$ & 6.30 & 1.94 \\
Coefficient in human capital production function, $\psi$ & 0.6 & 0.3 \\
Fraction of the old working, $\omega$ & 0.33 & 0.86 \\
\hline Social Security & & \\
\hline Replacement rate, $\varrho$ & 0.6 & 0.6 \\
\hline Demographics & & \\
\hline Birth rate, $\gamma^{N}$ & 1.56 & 1.56 \\
Survival rate, $s$ & 0.69 & 0.69 \\
\hline \hline
\end{tabular}


Figure 5: Elasticity of $e$ with respect to $s$ : No Annuity Markets

(a) Benchmark concavity $(\psi=0.6)$

(i) constant $\tau$

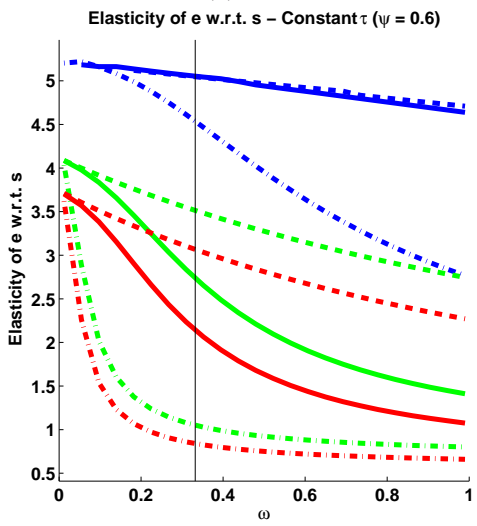

(ii) constant $\rho$

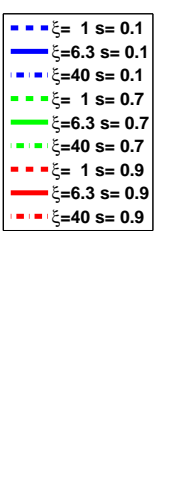

Elasticity of e w.r.t. $s-$ Constant $\rho(\psi=0.6)$

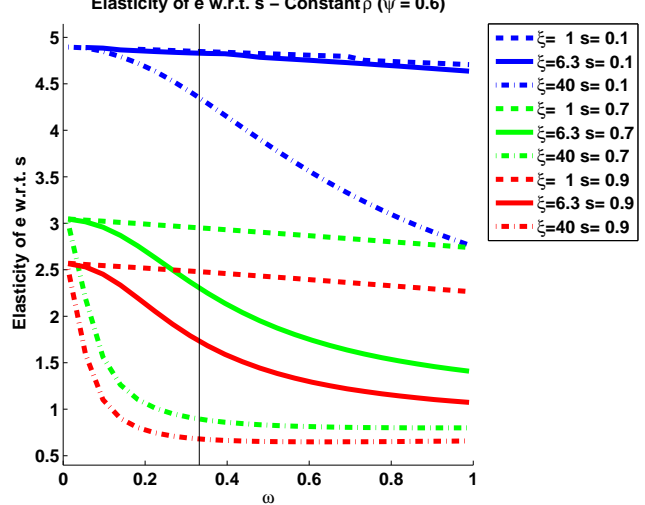

(b) Low concavity $(\psi=0.3)$

(i) constant $\tau$

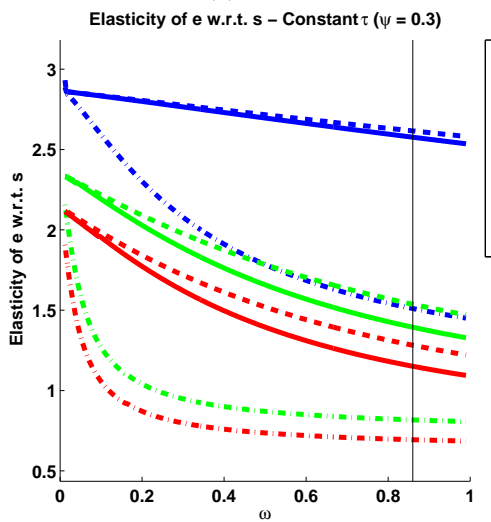

(ii) constant $\rho$

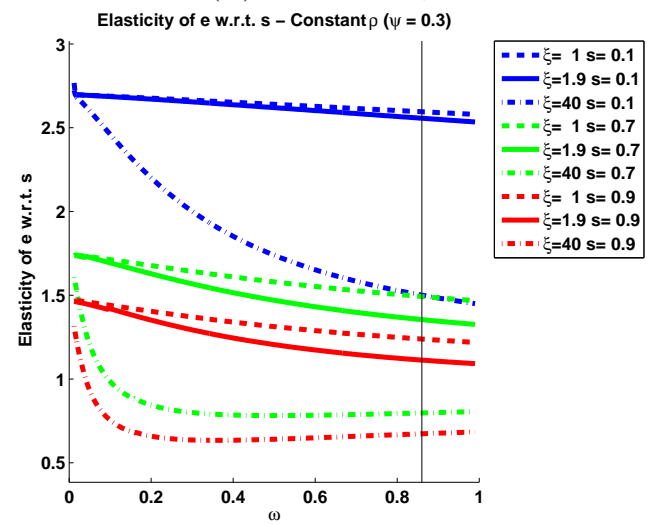


Figure 6: Elasticity of $e$ with respect to $\omega$ : No Annuity Markets

(a) Benchmark concavity $(\psi=0.6)$

(i) constant $\tau$

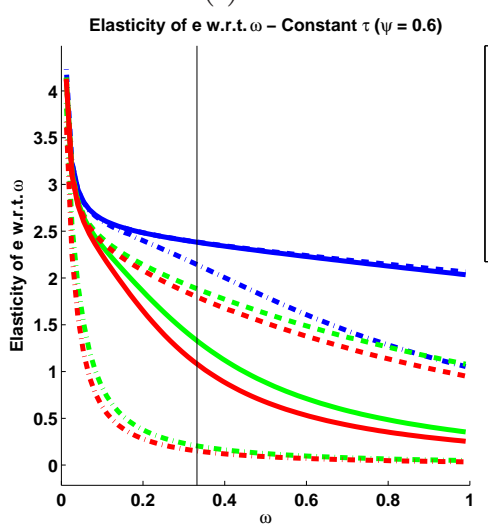

(ii) constant $\rho$

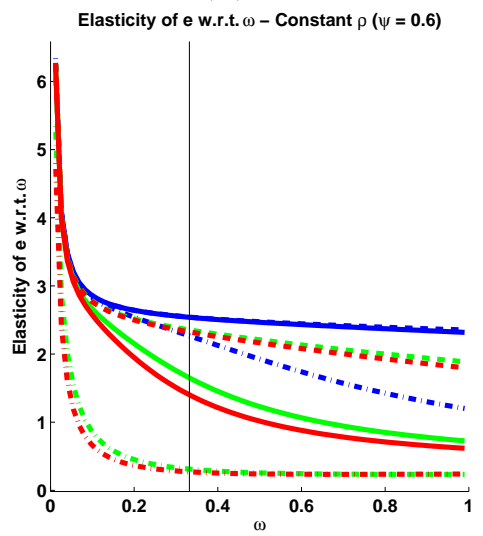

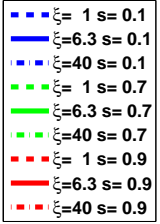

(b) Low concavity $(\psi=0.3)$

(i) constant $\tau$

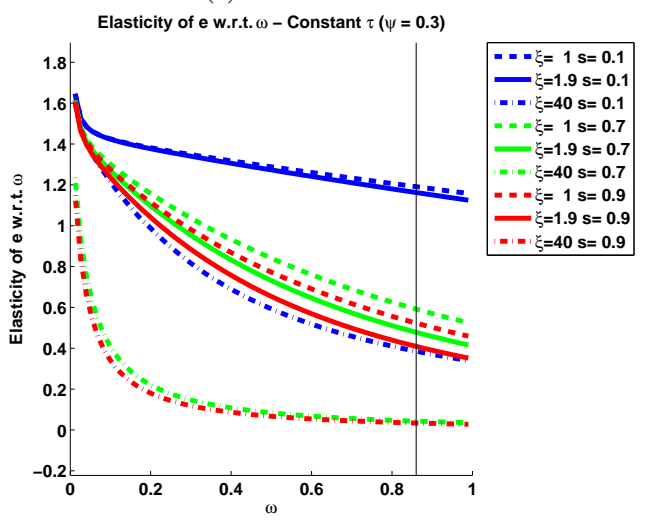

(ii) constant $\rho$

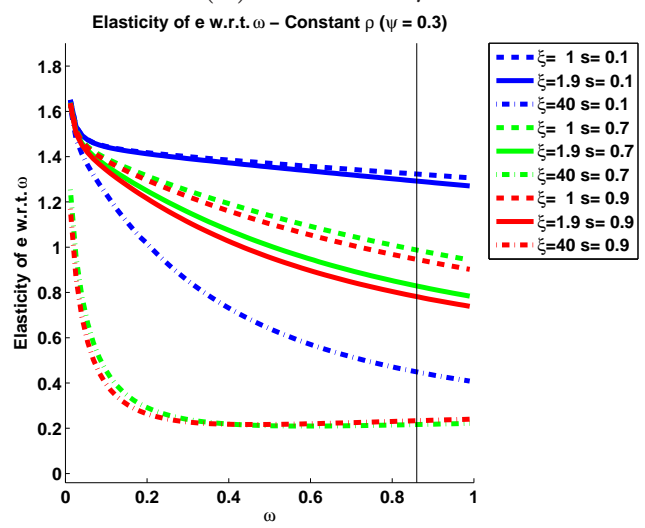




\section{References}

Attanasio, O. P. (1999). Consumption (John B. Taylor and Michael Woodford ed.)., Chapter 11, pp. 741-812. Handbook of Macroeconomics. Amsterdam: Elsevier.

Barro, R. J. and X. Sala-i-Martin (2003). Economic Growth. Cambridge: MIT Press.

Ben-Porath, Y. (1967). The Production of Human Capital and the Life Cycle of Earnings. Journal of Political Economy 75(4), 352-365.

Blanchard, O. J. (1985). Debt, Deficits, and Finite Horizons. Journal of Political Economy 93(2), 223-247.

Boucekkine, R., D. de la Croix, and O. Licandro (2002). Vintage Human Capital, Demographic Trends, and Endogenous Growth. Journal of Economic Theory 104, 340-375.

Bouzahzah, M., D. de la Croix, and F. Docquier (2002). Policy Reforms and Growth in Computable OLG Economies. Journal of Economic Dynamics and Control 26, 2093-2113.

Browning, M., L. P. Hansen, and J. J. Heckman (1999). Micro Data and General Equilibrium Models (J. Taylor and M. Woodford ed.)., Chapter 8, pp. 543-633. Handbook of Macroeconomics. Amsterdam: Elsevier.

Cutler, D., A. Deaton, and A. Lleras-Muney (2006). The Determinants of Mortality. Journal of Economic Perspectives 20(3), 97-120.

de la Croix, D. and O. Licandro (1999). Life Expectancy and Endogenous Growth. Economics Letters 65, 255-263.

Diamond, P. A. (1965). National Debt in a Neoclassical Growth Model. American Economic Review 55(5), 1126-1150.

Echevarria, C. A. and A. Iza (2006). Life Expectancy, Human Capital, Social Security and Growth. Journal of Public Economics 90, 2324-2349.

Eckstein, Z., P. Mira, and K. I. Wolpin (1999). A Quantitative Analysis of Swedish Fertility Dynamics. Review of Economic Dynamics 2, 137-165.

Flora, P., F. Kraus, and W. Pfenning (1983). State Economy and Society in Western Europe 1815-1975, Volume 1. Chicago: St. James Press.

Foster, A. D. and M. R. Rosenzweig (1996, September). Technical Change and HumanCapital Returns and Investments: Evidence from the Green Revolution. American Economic Review 86(4), 931-953.

Fougère, M. and M. Mérette (16). Population Ageing and Economic Growth in Seven OECD Countries, Volume 1999. Economic Modelling.

Hansen, G. D. and S. Imrohoroğlu (2008). Consumption over the life cycle: The role of annuities. Review of Economic Dynamics 11, 566-583.

Heijdra, B. J. and W. E. Romp (2008). AGEING AND GROWTH IN THE SMALL open economy. Journal of Economic Dynamics and Control. forthcoming. 
Hu, S.-C. (1999). Economic growth in the perpetual-youth model: Implications of the annuity market and demographics. Journal of Macroeconomics 21(1), 107-124.

Human Mortality Database (2008). University of California, Berkeley (USA), and Max Planck Institute for Demographic Research (Germany). www.mortality.org.

Hurd, M. D. (1990). Reseach on the Elderly: Economic Status, Retirement, and Consumption and Saving. Journal of Economic Literature 28(2), 565-637.

Kalemli-Ozcan, S., H. E. Ryder, and D. N. Weil (2000). Mortality decline, human capital investment, and economic growth. Journal of Development Economics 62, 1-23.

Ludwig, A., T. Schelkle, and E. Vogel (2008). Demographic Change, Education and Welfare. MEA Discussion Paper.

Mincer, J. (1995). Economic Development, Growth of Human Capital, and the Dynamics of the Wage Structure. Journal of Economic Growth 1, 29-48.

OECD (2008). Education at a Glance. Paris: OECD.

Ram, R. and T. W. Schultz (1979). Life Span, Health, Savings, and Productivity. Economic Development and Cultural Change 27(3), 399-421.

Sadahiro, A. and M. Shimasawa (2002). The Computable Overlapping Generations Model with Endogenous Growth Mechanism. Economic Modelling 20, 1-24.

The World Bank (2004). World Development Indicators 2004.

Willis, R. (1986). Wage determinants: a survey and reinterpretation of human capital earnings function (Orley Ashenfelter and Richard Layard ed.)., Chapter 10, pp. 525602. Handbook of Labor Economics. Amsterdam: Elsevier.

Yaari, M. E. (1965). Uncertain Lifetime, Life Insurance, and the Theory of the Consumer. The Review of Economic Studies 32(2), 137-150.

Zhang, J., J. Zhang, and R. Lee (2001). Mortality decline and long-run economic growth. Journal of Public Economics 80, 485-507. 


\section{Discussion Paper Series}

Mannheim Research Institute for the Economics of Aging, Universität Mannheim

To order copies, please direct your request to the author of the title in question.

\begin{tabular}{|c|c|c|c|}
\hline Nr. & Autoren & Titel & Jahr \\
\hline $166-08$ & $\begin{array}{l}\text { Alexander Ludwig } \\
\text { Michael Reiter }\end{array}$ & $\begin{array}{l}\text { Sharing Demographic Risk - Who is Afraid of } \\
\text { the Baby Bust? }\end{array}$ & 08 \\
\hline $167-08$ & $\begin{array}{l}\text { Jürgen Maurer } \\
\text { André Meier }\end{array}$ & $\begin{array}{l}\text { Smooth it Like the "Joneses?" Estimating Peer- } \\
\text { Group Effects in Intertemporal Consumption } \\
\text { Choice }\end{array}$ & 08 \\
\hline $168-08$ & $\begin{array}{l}\text { Melanie Lührmann } \\
\text { Jürgen Masurer }\end{array}$ & $\begin{array}{l}\text { Who wears the trousers? A semiparametric } \\
\text { analysis of decision power in couples }\end{array}$ & 08 \\
\hline $170-08$ & Jürgen Maurer & $\begin{array}{l}\text { Who has a clue to preventing the flu? } \\
\text { Unravelling supply and demand effects on the } \\
\text { take-up of influenza vaccinations }\end{array}$ & 08 \\
\hline $171-08$ & $\begin{array}{l}\text { Johannes Binswanger } \\
\text { Daniel Schunk }\end{array}$ & $\begin{array}{l}\text { What Is an Adequate Standard of Living } \\
\text { during Retirement? }\end{array}$ & 08 \\
\hline $172-08$ & $\begin{array}{l}\text { Mathis Schröder } \\
\text { Axel Börsch-Supan }\end{array}$ & Retrospective Data Collection in Europe & 08 \\
\hline $173-09$ & Michael Ziegelmeyer & $\begin{array}{l}\text { Documentation of the logical imputation using } \\
\text { the panel structure of the 2003-2008 German } \\
\text { SAVE Survey }\end{array}$ & 09 \\
\hline $174-09$ & $\begin{array}{l}\text { Axel Börsch-Supan, } \\
\text { Tabea Bucher-Koenen, } \\
\text { Martin Gasche und } \\
\text { Christina Benita Wilke }\end{array}$ & $\begin{array}{l}\text { Ein einheitliches Rentensystem für } \\
\text { Ost- und Westdeutschland - } \\
\text { Simulationsrechnungen zum Reformvorschlag } \\
\text { des Sachverständigenrates }\end{array}$ & 09 \\
\hline $175-09$ & $\begin{array}{l}\text { Steffen Reinhold, } \\
\text { Hendrik Jürges }\end{array}$ & Parental Income and Child Health in Germany & 09 \\
\hline $176-09$ & $\begin{array}{l}\text { Karsten Hank, Marcel } \\
\text { Erlinghagen }\end{array}$ & $\begin{array}{l}\text { Perceptions of Job Security in Europe's Ageing } \\
\text { Workforce }\end{array}$ & 09 \\
\hline $177-09$ & $\begin{array}{l}\text { Hendrik Jürges, } \\
\text { Karsten Hank, }\end{array}$ & $\begin{array}{l}\text { The Last Year of Life in Europe: Initial findings } \\
\text { from the SHARE study }\end{array}$ & 09 \\
\hline $178-09$ & Steffen Reinhold & $\begin{array}{l}\text { Reassessing the Link between Premarital } \\
\text { Cohabitation and Marital Instability }\end{array}$ & 09 \\
\hline $179-09$ & $\begin{array}{l}\text { Alexander Ludwig, } \\
\text { Edgar Vogel }\end{array}$ & $\begin{array}{l}\text { Mortality, Fertility, Education and Capital } \\
\text { Accumulation in a simple OLG Economy }\end{array}$ & 09 \\
\hline
\end{tabular}

